\title{
A new global optimum solution model based on multi-value dynamic programming for the cut-off grade optimization in a surface mining complex
}

\section{Pritam Biswas}

Indian Institute of Technology (Indian School of Mines): Indian Institute of Technology

Rabindra Kumar Sinha ( $\nabla$ rksinha@iitism.ac.in )

Indian Institute of Technology (Indian School of Mines), Dhanbad https://orcid.org/0000-0001-89714090

Phalguni Sen

Indian Institute of Technology (Indian School of Mines): Indian Institute of Technology

\section{Research Article}

Keywords: Dynamic programming, global optimum model, cut-off grade (COG), surface mining, NPV maximization

Posted Date: December 27th, 2021

DOI: https://doi.org/10.21203/rs.3.rs-1171028/v2

License: (c) (i) This work is licensed under a Creative Commons Attribution 4.0 International License. Read Full License 


\section{$\underline{\text { Title page }}$}

\section{Title of the Manuscript}

"A new global optimum solution model based on multi-value dynamic programming for the cut-off grade optimization in a surface mining complex"

Pritam Biswas ${ }^{1}$, Rabindra Kumar Sinha, ${ }^{2}$, Phalguni Sen ${ }^{3}$

\section{Author information}

\begin{tabular}{|c|c|c|}
\hline \multirow[t]{4}{*}{ First Author: } & $\begin{array}{l}\text { Name } \\
\text { Designation }\end{array}$ & $\begin{array}{l}\text { : Pritam Biswas } \\
: \text { Part-time research Scholar }\end{array}$ \\
\hline & Affiliation & $\begin{array}{l}\text { : Department of Mining Engineering, Indian Institute of } \\
\text { Technology (Indian School of Mines), Dhanbad, 826004, India }\end{array}$ \\
\hline & Email & : pritambiswas143sree@hotmail.com \\
\hline & ORCID & $:$ 0000-0002-3396-3386 \\
\hline \multirow[t]{5}{*}{ Second Author: } & Name & : Rabindra Kumar Sinha \\
\hline & Designation & : Assistant Professor \\
\hline & Affiliation & $\begin{array}{l}\text { : Department of Mining Engineering, Indian Institute of } \\
\text { Technology (Indian School of Mines), Dhanbad, 826004, India }\end{array}$ \\
\hline & Email & : rksinha@iitism.ac.in \\
\hline & ORCID & : 0000-0001-8971-4090 \\
\hline \multirow[t]{4}{*}{ Third Author: } & Name & : Phalguni Sen \\
\hline & Designation & : Professor (Retired) \\
\hline & Affiliation & $\begin{array}{l}\text { : Department of Mining Engineering, Indian Institute of } \\
\text { Technology (Indian School of Mines), Dhanbad, 826004, India }\end{array}$ \\
\hline & Email & : phalgunisen@yahoo.co.in \\
\hline
\end{tabular}

Corresponding author*

$\begin{array}{ll}\text { Name } & \text { : Rabindra Kumar Sinha } \\ \text { Affiliation } & : \text { Department of Mining Engg. IIT(ISM), Dhanbad, 826004, India. } \\ \text { Email } & : \text { rksinha@iitism.ac.in } \\ \text { ORCID } & : \text { 0000-0001-8971-4090 }\end{array}$




\section{Article Highlights}

- A new global optimum solution model based on multi-value dynamic programming (MDP) for the cut-off grade (COG) optimization for surface mining applications.

- This discrete COG-MDP model has the novelty of dealing with the simulation of eight different optimization possibilities to achieve the global maximum Net Present Value (NPV).

- A sequentially advancing algorithm has been developed for the simulation of the model for the mineral grades in the field of $C O G$ optimization.

- The computer model is developed in Python to contend with the complexities of processing a minimum of 500 series of dynamic variables associated with the complex system of mine, mill, and smelter and refinery with an accuracy value of $0.01 \%$ in grade bins. 


\section{A new global optimum solution model based on multi-value dynamic programming for the cut-off grade optimization in a surface mining complex}

Abstract

In techno-economic concern, cut-off grade ( $C O G$ ) optimization is the key for efficient mineral liquidation from the huge metalliferous surface mining sector. In this paper, a sequentially advancing algorithm based on discrete multi-value dynamic programming (MDP) has been developed to calculate the global optimum COG of a large-scale open-pit metalliferous deposit. The proposed $C O G$ optimization algorithm aims to overcome the limitations of straightforward classical techniques in determining the optimum COG. This discrete COG-MDP model is the first of its kind and has the novelty of dealing with the simulation of eight dynamic possibilities to achieve the maximal global Net Present Value (NPV). A high-level programming language (Python) has been used to develop the computer model to deal with the complexity of handling a minimum of 500 series of dynamic variables. This model can generate results in polynomial-time from the complex of mining, milling, and smelting and refining system corresponding to various limiting conditions. The prime objective considered in the model is to optimize the $C O G$ of a metalliferous deposit. A working open-pit copper mining complex from India has been used to validate the model. In this study, the optimum $C O G$ for the Malanjkhand copper deposit has been found to be $(0.33 \%, 0.23 \%, 0.52 \%, 0.26 \%, 0.27 \%, 0.22 \%, 0.24 \%)$ with a maximum NPV of ₹ $(12204,14653,16948,14609$, $21454,26717,38821)$ million corresponding to various scenarios. The findings also show that the present value gradually hits zero after the project's life cycle, confirming the typical pattern of other mining firms.

Keywords: Dynamic programming; global optimum model; cut-off grade $(C O G)$; surface mining; NPV maximization.

\section{Introduction}

Mineral resources are essential for contemporary society's socioeconomic development. Even though these commodities have been widely cross-referenced as "finite," their metal output has continuously risen throughout the ages. The twenty-first century has seen exponential resource extraction, corresponding to global economic expansion; consequently, long-term sustainable development is crucial. Global metal utilization is expanding at a rate of roughly 3.2\% per year, boosting trade and commerce (Krausmann et al., 2018; Van Vuuren et al., 1999). Metal mining has consistently been shown to be a significant source for meeting metal demands in infrastructure, health, information systems, and other services that can support economic growth (Jowitt et al., 2020). Thus, cutoff grade $(C O G)$ plays a significant role in achieving the objective of attaining techno-economic sustainability, which strives to maximize recovery utilization. The field of knowledge, exploration, findings, innovations, and technological progress required to meet a predetermined $\boldsymbol{C O G}$ has an impact on the ultimate achievable resource capacities. The worldwide average $\boldsymbol{C O G}$ for copper is approximately 0.49\% (Henckens \& Worrell, 2020; Mudd, 2012; Teseletso \& Adachi, 2021). 
Mineral economics is not a new field; this can be followed back 200 years to the research of classical economists like as Smith (Smith, 1776), Ricardo (Ricardo, 1821), and Jevons (Jevons, 1866), among others. Smith (Smith, 1776) noted that the demand for mineral resources appears to be unlimited due to customers' preferences and desire for manufactured products, which need a large number of fossil fuels and mineral resources to be exploited. Ricardo (Ricardo, 1821) highlighted that all mineral commodities are exposed to significant fluctuations, either temporary or permanent in nature, and of significant economic impact.

Surface mine planning is a dynamic and complicated system with a host of variables and multi-stages (Fig. 1), making it a complex problem that is hard to solve and demands a continuous financial risk assessment. Open-pit scheduling intends to find the best schedule of calendar programming across the mineral value cycle (Ali et al., 2021; Fathollahzadeh et al., 2021; Rezakhah \& Newman, 2020). This is because the value of a mining project is usually affected by various underlying economic and physical variables, such as commodity prices, grades, expenses, timetables, volumes, and environmental concerns, which are unknown with confidence at the project's inception.

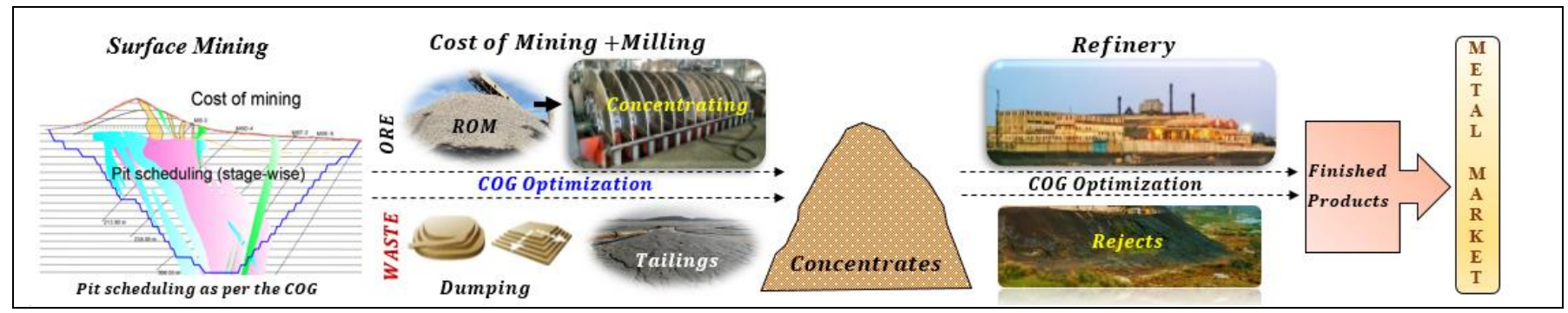

Fig. 1. A sequential multi-stages Surface mining operational flow diagram

\section{Literature Review}

Mining is a capital-intensive industry in which economic concerns dominate all activities. This is necessary for its long-term viability and growth. The $C O G$ of a mineral deposit is determined based on the techno-economic viability of production and profit obtained from the time a mine is opened until it is closed. COG is the lowest grade of ore that can be processed commercially. Therefore, this criterion creates a boundary inside a particular mineral deposit between ore and waste, either accepted for milling or rejected for dumping (Taylor, 1972, 1986).

In several contexts, mineral resources are classified as either ore or waste. The use of COG is a standard route to explore the ore-waste ratio and the total mineral content. All the COG optimization techniques can be divided broadly into traditional and modern methods. Traditional methods may further be divided into four major subcategories: mathematical programming, integer programming, linear programming, and nonlinear programming. On the other hand, modern techniques may be divided broadly into two major categories: the evolutionary algorithm and the Monte Carlo simulation.

Out of all the COG techniques, the maximum number of work may be attributed to the analytical approaches, but none can yield the optimal results. Henning (Henning, 1963) was the first who brought the idea of COG optimization into the mining business and a year later the seminal work of Lane (Lane, 1964) was introduced. Lane determined optimal COGs based on limited capacities, supporting Henning's (Henning, 1963) prediction that ideal COGs tend 
to drop with time. Henning's method keeps certain operational parameters fixed throughout the project's life cycle and does not account for the potential of capacity expansion. Following Lane's work, the amount of literature on the topic has expanded exponentially.

Through, globally the breakeven COG and Lane's (Lane, 1964, 1988) algorithm are being used commonly to maximize profit. However, maintaining a steady breakeven COG across the mine life would have serious consequences, potentially exposing the mining operation to considerably sub-optimal operating results. Lane's method also solved the breakeven model's flaws. It considered the production restrictions of various phases and the relevance of the grade-tonnage characteristics. Unfortunately, Lane's (Lane, 1964, 1988) method has been widely criticized for $C O G$ determination that may be more suitable in certain circumstances, making it possible to disregard the optimal estimates for COGs (Asad, 2005). Lane's technique has stayed empirical, necessitating the development and implementation of an analytical optimization technique (Dagdelen \& Kawahata, 2008, 2007). The application of mathematical programming to open-pit mine planning traces back to the $1960 \mathrm{~s}$. Acknowledging the limitations of Lane's approach, a few attempts have been made to overcome them through an alternative analytical framework of optimization (Azimi et al., 2012; Dagdelen \& Kawahata, 2008; Ganguli et al., 2011; Yasrebi et al., 2015). The basics of Lane's (Lane, 1964, 1988) technique have been expanded in most optimization approaches. Several studies employed time-value-of-money-based optimization approaches. The COG optimization algorithms that involve NPV maximization lead to better outcomes than those that maximizes the profit function.

Lane (Lane, 1988) effectively used the deterministic dynamic programming concepts to the optimization of COG policies. However, he advocated to find an optimal operating strategy and the associated maximum present value in a specific condition, the sum of the maximum present value surface is irrelevant. Every point along the optimal strategy path must be optimal, and all corresponding current values must be maxima. Assuming that future prices would vary, he proposed a dynamic programming method that can assure that the best $C O G$ is picked at all times. However, it can only be approximated by forecasting, which is fraught with risk. Dowd (Dowd, 1976) demonstrated the technique that might be used for stochastic data with the objective function of maximizing the present value of future net profits. Several conventional and meta-heuristic techniques are being applied extensively to optimize pit scheduling. Later, Wang (Q. Wang, 1995) and Tolwinski (Tolwinski, 1998) studied dynamic programming to study block sequencing. Due to the periodic extraction of finite resources, the efficiency of dynamic programming approaches has shown to be helpful in scheduling mining operations for simultaneous optimization of several policies (B. King, 2000). Linear programming, for example, might be used to maximize cash flow locally, whereas dynamic programming could be used to improve NPV on a global level.

Baidowi et al. (Baidowi et al., 2021) established a mathematical model for COG optimization in the open-pit metalliferous deposits based on overall profit maximisation, incorporating reclamation income and expenditures. The authors proposed the consideration of environmental variables in the determination of COGs. Few authors emphasized the importance and integration of blending optimization throughout the mining value chain (Chanda \& Dagdelen, 1995; Haonan et al., 2021; Jamshidi \& Osanloo, 2018). 
Dehghani and Bogdanovic (Dehghani \& Bogdanovic, 2018) used a bat algorithm to estimate metal price swings, which produced better outcomes than the traditional estimation approach for forecasting copper price. This resulted in a price trend. However, it is questionable when there is a significant and rapid shift in demand and supply or a technological upgrade or technology replacement. Surface miner, for example, is a technological substitute that reduces overall equipment expenditure by around half, eliminating the requirement of drilling, blasting, and crushing. A genetic algorithm was employed by Franco-sepulveda et al. (Franco-sepulveda et al., 2019) to maximize the $N P V$ of a mining operation. They looked at the price of the metal from a historical date to the present day and found that the sale value was $50 \%$ of the time lower than the projected value. Su et al. (Su et al., 2020) stated that the emergence and collapse of several price bubbles are connected to supposition, macroeconomic instability, a supply-demand imbalance, and economic turmoil. Tahar et al. (Tahar et al., 2021) agreed that commodities prices shocks might have differential effects. Most of the commodities' economies are highly volatile and difficult to anticipate. Considering an incorrect pricing forecast leads to sub-optimal COG selections and implications.

Russell (Russell, 1970) pioneered the concept of maximizing a project's NPV. The most commonly used economic metric in evaluating financial projects is NPV (Creemers, 2018; Peymankar et al., 2021). It is worth noting that NPV is acutely susceptible to revenue variations (Hustrulid et al., 2013; Oraee et al., 2011; Saleh \& Marais, 2006; Wiesemann et al., 2010). Ahmadi (Ahmadi, 2018) optimized the COG based on Lane's theory to maximize the $N P V$ using MATLAB. The optimum COG is the grade that maximizes the chosen objective function, usually the NPV (Asad \& Topal, 2011; Biswas et al., 2020). Various researchers (Ahmadi \& Shahabi, 2018; Bascetin \& Nieto, 2007; Qingfei Wang et al., 2010) have given several algorithms to determine optimum COG. They concluded that evaluating the $C O G$ based on maximizing the $N P V$ produces more accurate findings than the other methods. The COG that leads to the highest NPV for the project must be selected.

Determination of optimum $C O G$ is an essential and crucial aspect to exploit any metalliferous deposits efficiently and economically. Metal prices are dynamic in nature and follow an asymmetrical trend. So, one cannot fix the production schedule having a random $C O G$ without optimizing the objective function to reach the maximum $N P V$. The stage pits can be scheduled strategically and optimally once the ultimate pit has been set, keeping the maximum discounted and undiscounted block value in mind. The target of the strategic mine plan is to maximize NPV while adhering to all limitations (Jélvez et al., 2020; Samavati et al., 2018). If one doesn't optimize or check the COG periodically, there might be a time when the mine can face a cash crisis and needs to be shut off abruptly due to the possibility of negative $I R R$ in the long run. So, the mine planners should plan considering all the price dynamics, COGs, grade-tonnage ratio, reserve, and market scenario. At the end of the exploration stage, the ore body model is first finalized, and then the planning of mine development and project scheduling are carried out accordingly. A planning job requires a multitude of functions. In general, the mine planning comprises the steps as shown in the sequential flowchart of the whole process given below in Fig. 2. 


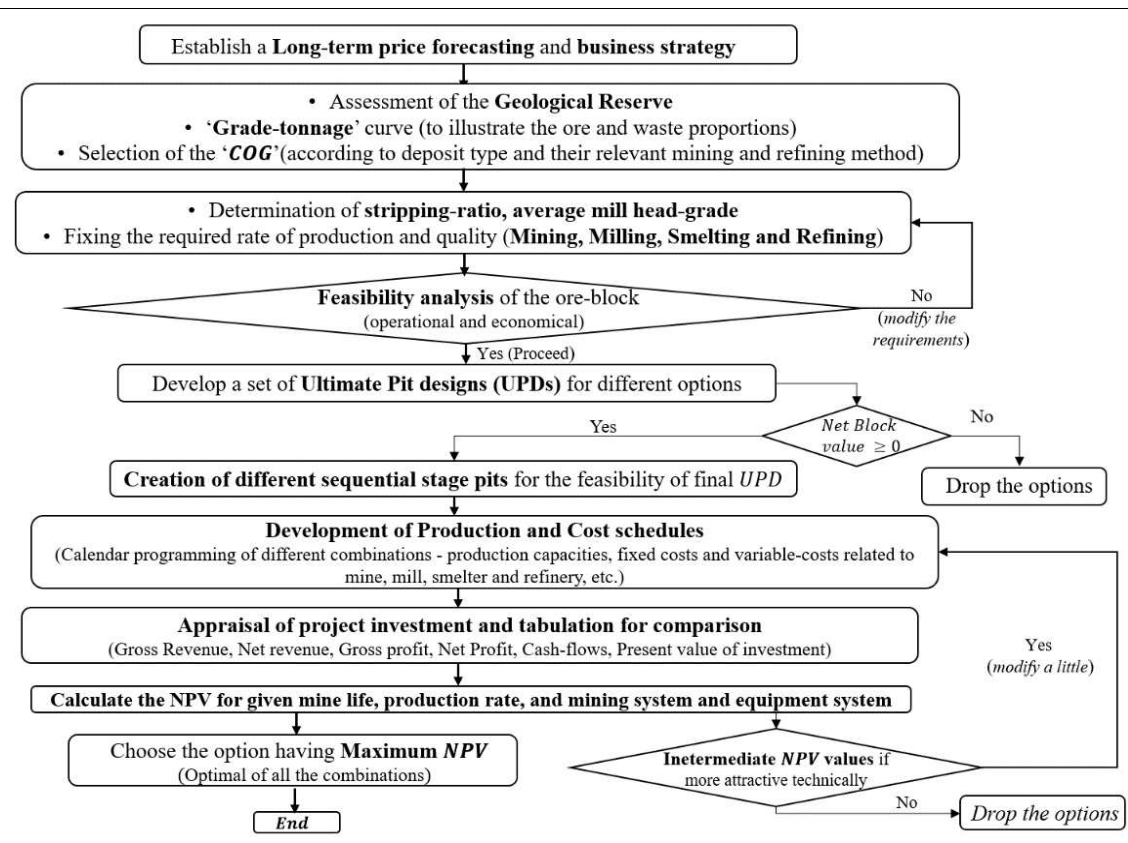

Fig. 2. The flowchart describes the procedural steps in mine planning.

\section{Optimization model framework}

The proposed multi-value dynamic programming $(M D P)$ framework has been established with the knowledge that the optimum COG for a surface mining complex is dynamic. A high-level programming language (Python) has been utilized for the simulation of the model. The entire set of mathematical programming is based on algebraic equations, calculus of variation, and stepwise computation that meet the requirements of a sequentially advancing algorithm to determine the global optimum COG. Real working data from the surface mining complex of Hindustan Copper Limited (HCL) has been used to validate the algorithm's efficacy and applicability.

\subsection{Functional model of multi-varying conditions}

The optimum COG in an open-pit metalliferous deposit is primarily influenced by three controlling capacity restrictions of several activities, namely mining, milling, smelting, and refining. While estimating the global optimum COG, eight alternative solutions may be explored based on the varied limiting factors and production capacity of the three phases. (Table 1).

Table 1 Eight dynamic models of potential combinations based on the multi-conditional scenario.

\begin{tabular}{lcccl}
\hline Models & $\begin{array}{c}\text { Mine } \\
\text { capacity }\end{array}$ & $\begin{array}{c}\text { Mill } \\
\text { capacity }\end{array}$ & $\begin{array}{c}\text { Refinery } \\
\text { capacity }\end{array}$ & $\begin{array}{l}\text { Restrictions or constraints } \\
(\boldsymbol{L}-\text { Limited } \text { and } \boldsymbol{U} \boldsymbol{L}-\text { Unlimited })\end{array}$ \\
\hline 1. & $U L$ & $U L$ & $U L$ & All capacities are unlimited \\
2. & $L$ & $U L$ & $U L$ & Mine capacity is limited \\
3. & $U L$ & $L$ & $U L$ & Mill (plant) capacity is limited \\
4. & $U L$ & $U L$ & $L$ & Refinery (smelter) capacity is limited \\
5. & $L$ & $L$ & $U L$ & Mine and mill capacities are limited \\
6. & $L$ & $U L$ & $L$ & Mine and refinery capacities are limited \\
7. & $U L$ & $L$ & $L$ & Mill and refinery capacities are limited \\
8. & $L$ & $L$ & $L$ & All (mine, mill and refinery) capacities are limited \\
\hline
\end{tabular}




\subsection{Model assumptions}

It is presumed that the whole reserve will be mined according to the grade dissemination, but only that fraction of the mined-out material that exceeds or equals the $C O G$ should be sent for concentration. Furthermore, the metal price, operational expenses, capital costs, rate of interest, tax percentage, and discount rate have all been assumed to be uniform during the life of mine. However, the volatility of the commodity price indices and technical developments might reshape the entire scenario of expenses related to excavation, processing and future revenue. To make the work comprehensible, it has been assumed that, at least on average, all ore mined within any twelve months will also be processed during that period.

\subsection{Model framework based on multi-value dynamic programming}

To determine the optimum $C O G$ for an open pit metalliferous deposits, one must express the problem as a mathematical programming model. The mathematical models for dealing with multi-varying COG or production scheduling are nonlinear discrete optimization models. The computational complexity of such issues necessitates the development of an efficient solution technique. The creation of the mathematical models and the solution technique have been described below.

The grade-tonnage $(g-t)$ variance of a mineral deposit is the input state of the framework with an individual domain $(G, T)$, as correlated in Fig. 3. For every range of $(\alpha, \beta)$, the $g$ - $t$ variance is distributed inside the range of $G_{\alpha, \beta}$ and $T_{\alpha, \beta}$. Therefore, the functional relation is given by $\boldsymbol{f}: G \rightarrow T$. All ' $G$ ' values shown under the grade-binds is set to ' $\boldsymbol{G}_{\boldsymbol{\alpha}, \boldsymbol{\beta}}$ '. For any ' $G$ ' values, there are a ' $T$ ' values corresponding to set $\left(T_{\alpha, \beta}\right)$; such that $\boldsymbol{T}_{\boldsymbol{\alpha}, \boldsymbol{\beta}}=\boldsymbol{f}\left(\boldsymbol{G}_{\boldsymbol{\alpha}, \boldsymbol{\beta}}\right)$ of Range, $R \in\left\{\boldsymbol{G}_{\boldsymbol{\alpha}, \boldsymbol{\beta}}, \boldsymbol{T}_{\boldsymbol{\alpha}, \boldsymbol{\beta}}\right\}$.

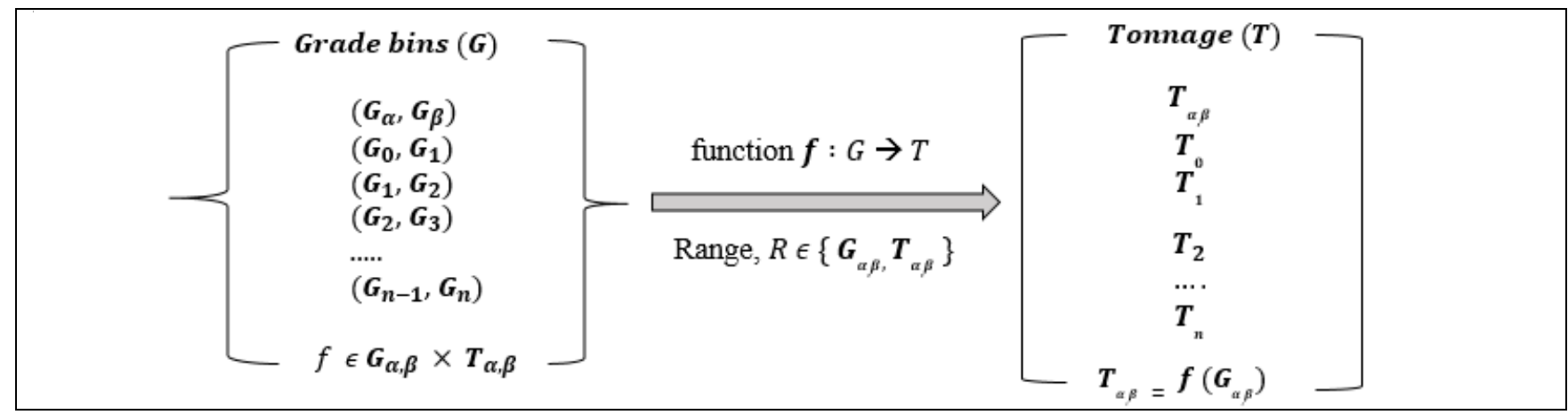

Fig. 3. Functional framework of $g$ - $t$ variance.

Here, the $\operatorname{COG}(\mathbb{C})$ for each set of ranges from $G_{\alpha, \beta}$ must be chosen, and the stages of transition from $\alpha$ to $\beta$ must be determined for every sequence of values. The values from individual stages are stored, and the optimization for the following state begins. COG is the lowest grade at which a metalliferous deposit may be extracted profitably (or processed). Material with a grade higher than COG is termed ore, whereas a material with a grade lower than COG is considered waste. 
The average grade $\left(\overline{\mathrm{g}}_{(\alpha, \beta)}\right)$ is determined from the $(g-t)$ variance of a mineral deposit and the concentration of metallic value present $(x)$ in it by following the weighted average formula expressed in equation (1)

$$
\overline{\mathrm{g}}_{(\alpha, \beta)}=f(x)=\frac{\int_{\alpha}^{\beta} G_{\alpha, \beta} \times T_{\alpha, \beta}(x) d x}{\int_{\alpha}^{\beta} T_{\alpha, \beta}(x) d x}
$$

The amount of ore $\left(T_{o}\right)$ and waste $\left(T_{w}\right)$ from the $(g-t)$ variance will be estimated from equations 2(a), 2(b), 2(c), and (3).

$$
\begin{aligned}
& T_{o(\alpha, \beta)}=0, \quad \text { where } G_{\alpha}<\mathbb{\mathbb { C }} \text {, and } G_{\beta} \leq \mathbb{\mathbb { C }}
\end{aligned}
$$

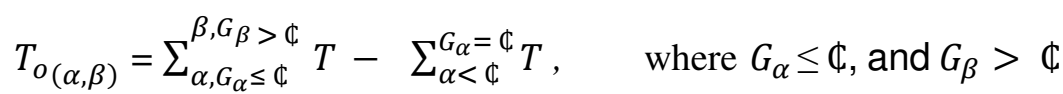

$$
\begin{aligned}
& T_{o(\alpha, \beta)}=\sum_{\alpha, G_{\alpha} \geq \mathbb{\Phi}}^{\beta, G_{\beta}>\mathbb{G}} T-\sum_{\alpha<\mathbb{\Phi}}^{G_{\alpha}=\mathbb{\mathbb { C }}} T, \quad \text { where } G_{\alpha} \geq \mathbb{C} \text {, and } G_{\beta}>\mathbb{C} \\
& T_{w_{(\alpha, \beta)}}=\sum_{\alpha}^{\beta} T-T_{o(\alpha, \beta)}
\end{aligned}
$$

Where $T$ is the total material $\left(T_{o}+T_{w}\right)$ to be mined out.

The stripping ratio $\left(\boldsymbol{S}_{\alpha, \beta}\right)$ is a fundamental parameter to be considered while calculating the $N P V$ of any mining complex. Mining professionals play a crucial part in determining $\mathbf{S}_{\alpha, \beta}$ figures related to their mine advancement, total ore-waste ratio, and whether to maintain the value constant or increase it in a trend that affects their NPVS. Equation (4) is used for the calculation of $\boldsymbol{S}_{\alpha, \beta}$.

$$
S_{\alpha, \beta}=\frac{T_{o(\alpha, \beta)}}{T_{w_{(\alpha, \beta)}}}
$$

Mining companies make money by mining mineral resources and refining them into marketable products. During operation, the mining complex incurred both variable and fixed expenses. The revenue is determined by the tonnes of ore treated, $\overline{\mathrm{g}}_{(\alpha, \beta)}$, the percent recoveries over-processing, and the product's current market value. Variable expenses are further divided into those related to mining and processing the ore and those related to digging and disposing of the waste. Drilling and blasting, transportation, disposal, restoration, and other expenditures are examples of variable expenses. General and administrative expenses and any additional costs that are not dependent on output are examples of fixed costs. The NPV may be calculated by discounting capital expenses and subtracting them from the discounted cash flow. Now sequentially utilizing all of the variables mentioned above, the $N P V_{\alpha, \beta}$ of a project is determined by equation (5):

$$
N P V_{\alpha, \beta}=P V_{\alpha, \beta}-C C_{\alpha, \beta}
$$

The original ruling criteria for all stages are $Q_{m_{(\alpha, \beta)},}, Q_{c_{(\alpha, \beta)},}, Q_{r_{(\alpha, \beta)}}$ for achieving the optimized returns $\left(N P V_{\alpha, \beta}\right)$, these input decision variables $\left(Q_{m_{(\alpha, \beta)}}, Q_{c_{(\alpha, \beta)}}, Q_{r_{(\alpha, \beta)}}\right)$ are regulated by the various limiting capacity functions. Depending upon the $\operatorname{COG}(\mathbb{C})$ and the stage transition $(\alpha \leq \psi \leq \beta)$, the tonnage of outputs at distinct stages, i.e., mining, milling, and smelting and refining, are estimated consequently by following any of the logical statement devised through equation (6) to (8). 
Subject to:

$$
\begin{array}{ll}
Q_{m} \leq M_{(\alpha, \beta)}(\alpha, \psi) & \forall n \\
Q_{c} \leq C_{(\alpha, \beta)}(\alpha, \psi) & \forall n \\
Q_{r} \leq R_{(\alpha, \beta)}(\alpha, \psi) & \forall n
\end{array}
$$

If $y$ is the overall metallurgical recovery, then

$$
Y_{\alpha, \beta}=Y_{m(\alpha, \beta)} \times Y_{c_{(\alpha, \beta)}} \times Y_{r_{(\alpha, \beta)}}
$$

Where:

$$
\begin{array}{ll}
P V_{\alpha, \beta} & =\text { present value cash flow } \\
C C_{\alpha, \beta} & =\text { cash flow } \\
\partial & =\text { discount rate } \\
n & =\text { period (year) indicator } \\
M_{(\alpha, \beta)} & =\text { maximum mining capacity (tonnes / yr) } \\
C_{\alpha, \beta} & =\text { maximum mill capacity to process ore (tonnes } / \mathrm{yr} \text { ) } \\
R_{(\alpha, \beta)} & =\text { maximum refinery capacity of metal production (tonnes } / \mathrm{yr} \text { ) } \\
Q_{m} & =\text { actual mine production rate (ore and waste) (tonnes / yr) } \\
Q_{c} & =\text { actual ore processing rate in the mill (tonnes / yr) } \\
Q_{r} & =\text { actual metal production rate in the refinery (tonnes } / \mathrm{yr}) \\
Y_{m(\alpha, \beta)} & =\text { mining recovery } \\
Y_{C(\alpha, \beta)} & =\text { mill recovery } \\
Y_{r_{(\alpha, \beta)}} & =\text { refinery recovery }
\end{array}
$$

Generally, COG optimization has been observed as a nonlinear dynamic system and can be solved using Dynamic Programming (DP) to obtain a globally optimum solution. The basic concept behind DP is to break down the optimization issue into a series of sub-problems, each representing the optimization of a single control action at a particular time. The value function, which translates the current state of the system to the $N P V$ of future income, connects these sub-problems. The best control action at each time can be obtained by solving a sub-problem at that moment after the value function has been computed. These sub-problems are, in general, significantly easier than the original optimization issue; each sub-global problem's optimum may be quantified effectively.

\section{Module 1: All Unlimited Conditions}

When all the three stages are unlimited, it brings the most exciting and novel part of the optimization combination. This is being the first mathematical approach, which deals with all the unlimited capacities. Here all the three components $C O G$, mine production, and mine-life, have been optimized simultaneously at the same time to determine the optimal COG. Here, for each of the $C O G$ - the corresponding ore-waste tonnage, stripping ratio, average grade, and cumulative tonnage has been calculated. Each COG value will be optimized starting with the total tonnage as the mine production from year 1 to 100 . This $C O G$ - mine life and mine production optimization will give the year-wise production rate for the same $C O G$ value for years 1 to 100 . After that, the $N P V$ is calculated from year 1 to 100 for the same COG value. This whole process will be repeated for all the COG values of the grade-tonnage distribution curve. After this, there will be a final set of data from all the $C O G$ values having their 
maximum $N P V S$ with their corresponding optimal mine life and production; among all the optimum $C O G$ values, the one with the highest $N P V$ is the global optimum $C O G$.

The following assumptions, as given below, have been made for the sequence of working.

1. The activity time frame is deterministic.

2. The per-period resource requirements for activities and project resource availability are set and known.

3. The cash flow associated with each activity is not susceptible to change in the course; hence, no stochastic values have been used for the determination of $C O G$.

4. There is no interruption in the performance of the activity once it has begun (no pre-emption).

5. No cancellations are permitted. Each activity must be finished to check its optimality performance.

6. Each activity is completed following the sequentially advancing algorithm. That paradigm is associated with a predictable activity length, fixed resource requirements, and a set cash flow.

7. When an activity is completed, net non-negative cash flows will occur.

8. The stockpiling option has not been considered.

Under the prior assumptions, the $C O G$ optimization aims to maximize the project's $N P V$ and is expressed as mathematical programming; the following problem statements are developed in the form of equations to solve the dynamic $C O G$ optimality scenario.

Maximize $\rightarrow N P V_{(\alpha, \beta)}$ subject to $\sum_{\operatorname{cog}_{(\alpha, \beta)}=0}^{\operatorname{cog}_{(\alpha, \beta)}=n} \sum_{t_{(\alpha, \beta)}=1}^{t_{(\alpha, \beta)}=n} \sum_{Q_{m(\alpha, \beta)}}^{Q_{m_{(\alpha, \beta)}} \epsilon t_{(\alpha, \beta)}=n}$

Maximize: $\sum_{a=0}^{N} \sum_{\operatorname{cog}_{(\alpha, \beta)}=0}^{\operatorname{cog}_{(\alpha, \beta)}=n} \sum_{t_{(\alpha, \beta)}=1}^{t_{(\alpha, \beta)}=n} \sum_{Q_{m_{(\alpha, \beta)}} \epsilon t_{(\alpha, \beta)}=1}^{Q_{m_{(\alpha, \beta)}} \epsilon t_{(\alpha, \beta)}=n} \cdot N P V_{(\alpha, \beta)} \cdot j_{a t} . \partial_{t}^{a}$

Subject to:

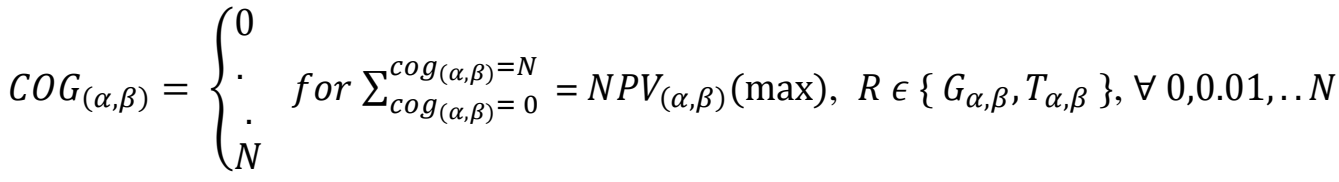

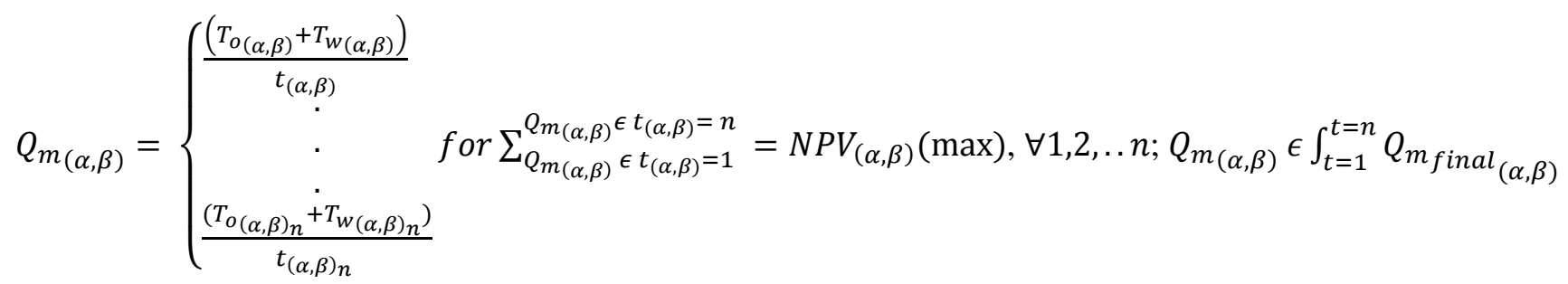

Besides the optimization technique mentioned above for the determination of $Q_{m(\alpha, \beta)}$, the empirical-formulae based mining production rates have also been determined for the comparison and efficacy of the model utilizing the existing thumb rule given by Taylor (Taylor, 1986) and the modified Taylor's rule by Long (Long, 2009).

$$
\begin{aligned}
& \text { Mine }- \text { life }_{(\alpha, \beta) \text { Talylor }} \cong 6.5 \times(\text { Ore tonnage in millions })^{\frac{1}{4}} \\
& Q_{m_{(\alpha, \beta) \text { Taylor }}}=\left\{\frac{\left(T_{o_{(\alpha, \beta)}}+T_{\left.w_{(\alpha, \beta)}\right)}\right.}{\text { Mine-life }(\alpha, \beta) \text { Talylor }}\right\}
\end{aligned}
$$




$$
\begin{aligned}
& Q_{m(\alpha, \beta) \text { Long }}=0.123 * \text { tonnage } 0.649 * 350 \\
& t_{(\alpha, \beta)}=\left\{\begin{array}{l}
1 \\
2 \\
\cdot \\
\cdot \\
n
\end{array} \text { for } \sum_{t_{(\alpha, \beta)}=1}^{t_{(\alpha, \beta)}=n}=N P V_{(\alpha, \beta)}(\max ), t_{(\alpha, \beta)} \in\{1, n\},, \forall 1,2, \ldots . n\right.
\end{aligned}
$$

Where, $j_{a t}=\left\{\begin{array}{c}1 \text { if action ' } a \text { ' is finished in time ' } n \text { ', a multi value }- \text { sequential stages } \\ 0 \text { otherwise, though no interruption in the completion of an action }\end{array}\right.$

$\partial=$ The discount factor over $n$ periods

The target function is to maximize the total of the present values of the activities' contributions discounted back to the project's commencement date. The total of the future values of the cash flows connected with the various phases (periods) of that activity, discounted to the end of the action, less the opportunity cost of the recovered investment capital required by the action, is the contribution of that activity. This figure is derived from:

$$
\begin{aligned}
& N P V_{(\alpha, \beta)}=\operatorname{Max} \int_{\operatorname{cog}_{(\alpha, \beta)}=0}^{\operatorname{cog}_{(\alpha, \beta)}=n} \int_{t_{(\alpha, \beta)}=1}^{t_{(\alpha, \beta)}=n} \int_{Q_{m(\alpha, \beta)} \epsilon t_{(\alpha, \beta)}=1}^{Q_{m(\alpha, \beta)} \epsilon t_{(\alpha, \beta)}=n} \quad\left[\left\{P V_{(\alpha, \beta)}-C C_{(\alpha, \beta)}\right\} e^{-\partial t} d t\right] \\
& \alpha \leq \mathbb{C} \leq \beta
\end{aligned}
$$

According to the mine-life, we calculate the production capacities and the following stage capacities, and then it follows the sequentially advancing optimization approach to determine the optimal COG value. Ultimately, the grade at which it contributes the Global maximal NPV value decides the global optimal COG value. The overview of the multi-value driven nested $D P$ algorithmic approach is shown in Fig. 4.

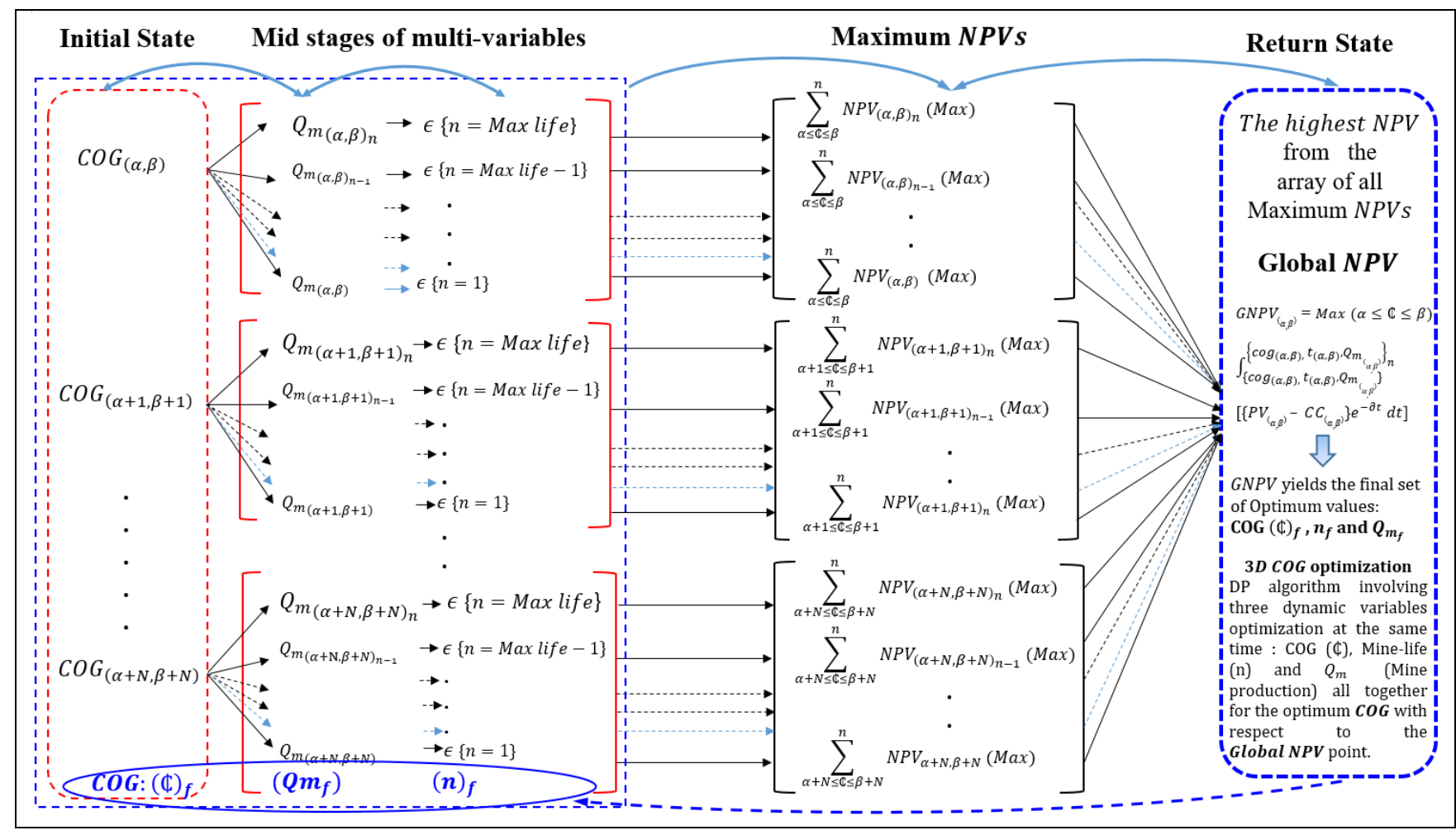

Fig. 4. An overview of the multi-value driven nested dynamic programming algorithmic approach. 
Module II: When mining capacity is limited and the rest two stages are unlimited, then the maximum value of $N P V$ from the array is considered, neglecting that production rate is less than production capacity, taking the corresponding $C O G$, and deciding the final capacities of the rest two stages.

When the capacity of mining is the controlling factor, then the decision state is, $Q_{m} \leq M_{(\alpha, \beta)}(\alpha, \psi) \forall n$; Accordingly, the $Q_{m(\alpha, \beta)}, Q_{c(\alpha, \beta)}, Q_{r(\alpha, \beta)}$ are calculated using equations (16) through (18).

$$
\begin{aligned}
& Q_{m_{(\alpha, \beta)}}=T_{o_{(\alpha, \beta)}}+T_{w_{(\alpha, \beta)}} \\
& Q_{c_{(\alpha, \beta)}}=\frac{Q_{m_{(\alpha, \beta)}}}{\left\{1+S_{(\alpha, \beta)}\right\}} \times Y_{m_{(\alpha, \beta)}} \\
& Q_{r_{(\alpha, \beta)}}=Q_{c_{(\alpha, \beta)}} \times \overline{\mathrm{g}}_{(\alpha, \beta)} \times Y_{c_{(\alpha, \beta)}} \times Y_{r_{(\alpha, \beta)}}
\end{aligned}
$$

Module III: When mining capacity and smelter \& refinery capacities are unlimited, and mill capacity is limited, then the maximum value of $N P V$ from the array is considered where the mill production is less than or equal to the mill capacity and take the corresponding $C O G$, and hence deciding the final output from the rest two unlimited stages.

When the capacity of milling is the controlling factor, then the decision state is, $Q_{C} \leq C_{(\alpha, \beta)}(\alpha, \psi) \forall n$; Accordingly, the $Q_{m_{(\alpha, \beta)}}, Q_{c_{(\alpha, \beta)}}, Q_{r_{(\alpha, \beta)}}$ are calculated using equations (19) through (20).

$$
\begin{aligned}
& Q_{m(\alpha, \beta)}=\left(\frac{T_{o(\alpha, \beta)}+T_{w(\alpha, \beta)}}{T_{o(\alpha, \beta)}}\right) \times Q_{c_{(\alpha, \beta)}} \times\left(\frac{1}{Y_{m(\alpha, \beta)}}\right) \\
& Q_{r_{(\alpha, \beta)}}=Q_{c_{(\alpha, \beta)}} \times \overline{\mathrm{g}}_{(\alpha, \beta)} \times Y_{c_{(\alpha, \beta)}} \times Y_{r_{(\alpha, \beta)}}
\end{aligned}
$$

Module IV: When mining capacity and mill capacity are unlimited, and smelter and refinery capacity is limited, then the maximum value of $N P V$ from the array is considered, which satisfies the condition that corresponding smelter and refinery production is less than or equal to the smelter and refinery capacity and take the corresponding COG, and hence deciding the final output from the rest two unlimited stages.

When the capacity of smelting $\&$ refining is the regulating factor, then the decision state is, $Q_{r} \leq R_{(\alpha, \beta)}(\alpha, \psi)$ $\forall n$;

Accordingly, the $Q_{m(\alpha, \beta)}, Q_{c(\alpha, \beta)}, Q_{r(\alpha, \beta)}$ are calculated using equations (21) through (22).

$$
\begin{aligned}
& Q_{c_{(\alpha, \beta)}}=\left(\frac{Q_{r_{(\alpha, \beta)}} \times Y_{r_{(\alpha, \beta)}}}{\bar{g}(\alpha, \beta)}\right) \\
& Q_{m_{(\alpha, \beta)}}=\left(\frac{T_{o(\alpha, \beta)}+T_{w(\alpha, \beta)}}{T_{o(\alpha, \beta)}}\right) \times Q_{c_{(\alpha, \beta)}} \times\left(\frac{1}{Y_{m(\alpha, \beta)}}\right)
\end{aligned}
$$

Module V: When mining capacity and mill capacity are limited, and smelter \& refinery capacity is unlimited, then the maximum value of $N P V$ from the array is considered that satisfies the condition that corresponding mine production and mill production is less than or equal to their capacity and take the corresponding $C O G$, and hence deciding the final smelter and refinery capacity.

When the capacity of mining and milling are the controlling factors, then the decision state is, $Q_{m} \leq M_{(\alpha, \beta)}(\alpha, \psi)$ $\forall n$ and, $Q_{C} \leq C_{(\alpha, \beta)}(\alpha, \psi) \forall n ;$ 
Accordingly, the al $Q_{m_{(\alpha, \beta)}}, Q_{c_{(\alpha, \beta)}}, Q_{r_{(\alpha, \beta)}}$ are calculated using equations (23) through (24).

$$
\begin{aligned}
& Q_{c_{(\alpha, \beta)}}=\frac{Q_{m_{(\alpha, \beta)}}}{\left\{1+S_{(\alpha, \beta)}\right\}} \times Y_{m_{(\alpha, \beta)}} \\
& Q_{r_{(\alpha, \beta)}}=Q_{c_{(\alpha, \beta)}} \times \overline{\mathrm{g}}_{(\alpha, \beta)} \times Y_{c_{(\alpha, \beta)}} \times Y_{r_{(\alpha, \beta)}}
\end{aligned}
$$

Module VI: When mining capacity and smelter capacity are limited, and mill capacity is unlimited, then the maximum value of $N P V$ is considered from the array that satisfies the condition that corresponding mine production and smelter production is less than or equal to their capacity and take the corresponding $C O G$, and hence deciding the mill capacity.

When the capacity of mining and refining are the controlling factors, then the decision state is, $Q_{m} \leq$ $M_{(\alpha, \beta)}(\alpha, \psi) \forall n$ and, $Q_{r} \leq R_{(\alpha, \beta)}(\alpha, \psi) \forall n ;$

Accordingly, the $Q_{m(\alpha, \beta)}, Q_{c_{(\alpha, \beta)}}, Q_{r_{(\alpha, \beta)}}$ are calculated using equations (25) through (26).

$$
\begin{aligned}
& Q_{c_{(\alpha, \beta)}}=\frac{Q_{m_{(\alpha, \beta)}}}{\left\{1+S_{(\alpha, \beta)}\right\}} \times Y_{m_{(\alpha, \beta)}} \\
& Q_{r_{(\alpha, \beta)}}=Q_{c_{(\alpha, \beta)}} \times \overline{\mathrm{g}}_{(\alpha, \beta)} \times Y_{c_{(\alpha, \beta)}} \times Y_{r_{(\alpha, \beta)}}
\end{aligned}
$$

Module VII: When milling capacity and smelter and refinery capacity are limited, and mine production capacity is unlimited, then the maximum value of $N P V$ is considered from the array that satisfies the condition that corresponding mill, smelter and refinery production is less than or equal to their capacities and take the corresponding $C O G$, and hence deciding the final mine capacity.

When the capacity of the milling and refining are the controlling factors, then the decision state is, $Q_{c} \leq$ $C_{(\alpha, \beta)}(\alpha, \psi) \forall n$ and, $Q_{r} \leq R_{(\alpha, \beta)}(\alpha, \psi) \forall n ;$

Accordingly, the $Q_{m_{(\alpha, \beta)}}, Q_{c_{(\alpha, \beta)}}, Q_{r_{(\alpha, \beta)}}$ are calculated using equations (27) through (28).

$$
\begin{aligned}
& Q_{m_{(\alpha, \beta)}}=\left(\frac{T_{o_{(\alpha, \beta)}}+T_{w(\alpha, \beta)}}{T_{o(\alpha, \beta)}}\right) \times Q_{c(\alpha, \beta)} \times\left(\frac{1}{Y_{m_{(\alpha, \beta)}}}\right) \\
& Q_{r_{(\alpha, \beta)}}=Q_{c_{(\alpha, \beta)}} \times \overline{\mathrm{g}}_{(\alpha, \beta)} \times Y_{c_{(\alpha, \beta)}} \times Y_{r_{(\alpha, \beta)}}
\end{aligned}
$$

Module VIII: When all the three stages are limited, the maximum value of $N P V$ from the array that satisfies the condition corresponding to all three-production stages will be considered. Among the three stages, the minimum capacity stage is the determining factor to decide the final output from the rest two stages, and thus the corresponding calculation will take place.

When all the capacities of mining, milling and smelting and refining are the controlling factors, then the decision state is, $Q_{m} \leq M_{(\alpha, \beta)}(\alpha, \psi) \forall n, Q_{c} \leq C_{(\alpha, \beta)}(\alpha, \psi) \forall n$ and, $Q_{r} \leq R_{(\alpha, \beta)}(\alpha, \psi) \forall n$;

Accordingly, the $Q_{m(\alpha, \beta)}, Q_{c(\alpha, \beta)}, Q_{r_{(\alpha, \beta)}}$ are calculated using equations (29) through (30).

$$
\begin{gathered}
Q_{c_{(\alpha, \beta)}}=\frac{Q_{m_{(\alpha, \beta)}}}{\left\{1+S_{(\alpha, \beta)}\right\}} \times Y_{m_{(\alpha, \beta)}} \\
Q_{r_{(\alpha, \beta)}}=Q_{c_{(\alpha, \beta)}} \times \bar{g}_{(\alpha, \beta)} \times Y_{c_{(\alpha, \beta)}} \times Y_{r_{(\alpha, \beta)}}
\end{gathered}
$$


Ultimately the grade at which it contributes the maximal $N P V$ value decides the global optimal COG value.

The given stage-wise logical conditions are implied to all the eight modules for obtaining the final $Q_{m f}(\alpha, \beta), Q_{c f}(\alpha, \beta), Q_{r f}(\alpha, \beta)$ values according to the various limiting conditions from the set of mining, milling, smelting and refining.

\section{Stage - I:}

When mining capacity is the ruling unit, then the decision state is, $Q_{m} \leq M_{(\alpha, \beta)}(\alpha, \psi) \forall n$;

Accordingly, the $Q_{m_{(\alpha, \beta)},} Q_{c(\alpha, \beta)}, Q_{r(\alpha, \beta)}$ are calculated using equations (31) through (33).

$$
\begin{aligned}
& Q_{m(\alpha, \beta)}=T_{o_{(\alpha, \beta)}}+T_{w_{(\alpha, \beta)}} \\
& Q_{c_{(\alpha, \beta)}}=\frac{Q_{m_{(\alpha, \beta)}}}{\left\{1+S_{(\alpha, \beta)}\right\}} \times Y_{m_{(\alpha, \beta)}} \\
& Q_{r_{(\alpha, \beta)}}=Q_{c_{(\alpha, \beta)}} \times \overline{\mathrm{g}}_{(\alpha, \beta)} \times Y_{c_{(\alpha, \beta)}} \times Y_{r_{(\alpha, \beta)}}
\end{aligned}
$$

Where $\bar{g}_{(\alpha, \beta)}$ is the average mill-head grade.

\section{Stage - II:}

When milling and refining capacities are the ruling units, then the decision state is $Q_{c(\alpha, \beta)}>C_{\alpha, \beta}$ or $Q_{r_{(\alpha, \beta)}}>$ $R_{\alpha, \beta}$ accordingly,

$$
Q_{m(\alpha, \beta)} \text {, and } Q_{r_{(\alpha, \beta)}} \text {, which are calculated using equations (34) and (35); }
$$$$
Q_{c} \leq C_{(\alpha, \beta)}(\alpha, \psi) \quad \forall n \quad ;
$$$$
Q_{m(\alpha, \beta)}=\frac{Q_{c(\alpha, \beta)} \times\left\{1+S_{(\alpha, \beta)}\right\}}{Y_{m(\alpha, \beta)}}
$$

$$
Q_{r_{(\alpha, \beta)}}=Q_{c_{(\alpha, \beta)}} \times \overline{\mathrm{g}}_{(\alpha, \beta)} \times Y_{c_{(\alpha, \beta)}} \times Y_{r_{(\alpha, \beta)}}
$$

\section{Stage - III:}

When refining and mining capacities are the ruling units, then the decision state is accordingly either.

$$
\begin{aligned}
& Q_{r_{(\alpha, \beta)}}>R_{\alpha, \beta} \text { or } \quad Q_{m_{(\alpha, \beta)}}>M_{\alpha, \beta} \\
& Q_{r} \leq R_{(\alpha, \beta)}(\alpha, \psi) \quad \forall n \quad ;
\end{aligned}
$$

The value of $Q_{c_{(\alpha, \beta)}}$ and $Q_{r_{(\alpha, \beta)}}$ are calculated using equations (36) and (37).

$$
\begin{aligned}
Q_{c_{(\alpha, \beta)}} & =\frac{Q_{r_{(\alpha, \beta)}}}{\frac{\overline{\mathrm{g}}(\alpha, \beta)}{Y_{c_{(\alpha, \beta)}} \times Y_{r_{(\alpha, \beta)}}}} \\
Q_{r_{(\alpha, \beta)}} & =\frac{Q_{\left.c_{\alpha, \beta}\right)}}{Y_{m_{(\alpha, \beta)} \times\left\{1+S_{(\alpha, \beta)}\right\}}}
\end{aligned}
$$

Following the stage transition, the decision variables $\left(Q_{m_{(\alpha, \beta)}}, Q_{c_{(\alpha, \beta)}}, Q_{r_{(\alpha, \beta)}}\right)$ are stored as the final or ultimate decision variables $\left(Q_{m f}(\alpha, \beta), Q_{c f_{(\alpha, \beta)}}, Q_{r f}(\alpha, \beta)\right)$ and will now be the optimum solutions for each $(\alpha, \beta)$ state of variables. These decision variables will now be utilized to calculate the project's concentrates (tonnes/yr), 
tailings (tonnes/yr), metal content (tonnes/yr) and (tonnes/yr), as shown through the equations (38) to (41). Following each stage of the computation, one must optimize the final value.

$$
\begin{aligned}
& \text { Concentrate }_{(\alpha, \beta)}=\frac{Q_{c_{(\alpha, \beta)}} * \overline{\mathrm{g}}_{(\alpha, \beta)} * Y_{C_{(\alpha, \beta)}}}{\mathbb{\Phi}_{g}(\%)} \\
& \operatorname{Tailings}_{(\alpha, \beta)}=Q_{m_{(\alpha, \beta)}}-\text { Concentrate }_{(\alpha, \beta)} \\
& \operatorname{Metal}_{(\alpha, \beta)}=Q_{r_{(}(\alpha, \beta)} \\
& \operatorname{Slag}_{(\alpha, \beta)}=\text { Concentrate }_{(\alpha, \beta)}-\text { Metal }_{(\alpha, \beta)}
\end{aligned}
$$

The selection of the optimal COG is followed by a multi-staged sequential decision problem (Li \& Yang, 2012; Biswas et al., 2020) with the output from each state feeding as an input for the following stages. Each stage has multiple different states correlated with it, as illustrated in Fig. 5.

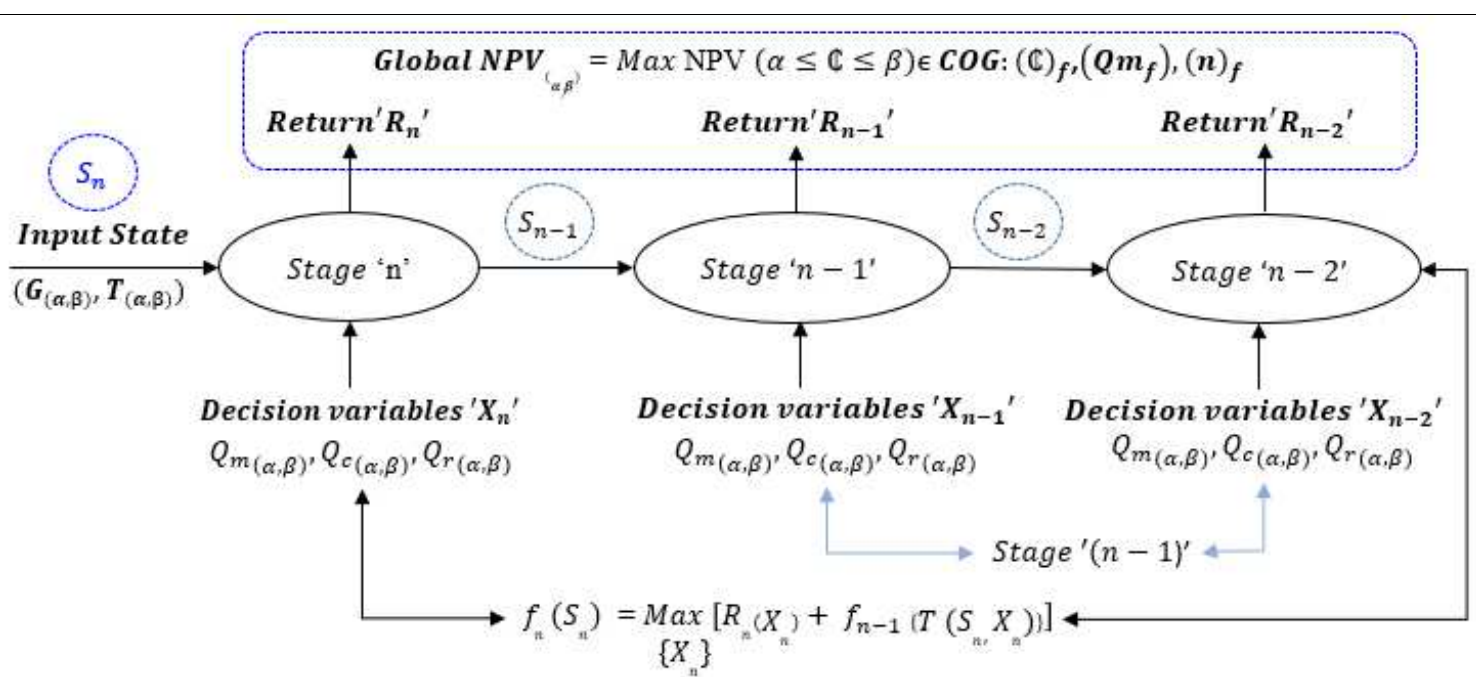

Fig. 5. The multi-value dynamic programming framework for the multi-stage decision sequence for ' $n$ ' stages.

Bellman's principle of Optimality (Bellman, 1972) governs the optimization of the output throughout all stages. State variables $\left(S_{n(\alpha, \beta)}\right)$ and Decision Variables $\left(Q_{m_{(\alpha, \beta)}}, Q_{c_{(\alpha, \beta)}}, Q_{r_{(\alpha, \beta)}}\right)$ have discrete values. The optimal decision at stage ' $n$ ', for the state ' $S_{n}$ ' is determined by a recursive relation. It provides the decision for every state at stage $(n-1)$. In this case, $f_{n}\left(S_{n}\right)$ is the optimized objective function value at stage ' $n$ ' and ' $X_{n}$ ' is the decision that maximizes over $\left\{X_{n}\right\}$.

$$
\begin{aligned}
f_{n}\left(S_{n}\right)= & \operatorname{Max}\left[R_{n}\left(X_{n}\right)+f_{n-1}\left\{T\left(S_{n}, X_{n}\right)\right\}\right] \\
& \left\{X_{n}\right\}
\end{aligned}
$$

$R_{n}$ : Return for the decision, ' $\mathrm{X}_{\mathrm{n}}$ ' in the present state.

$T\left(S_{n}, X_{n}\right)$ : Transfer function to obtain the state ' $S_{n-1}$ ' related to ' $S_{n}$ ' and ' $X_{n}$ '.

There are returns after every stage, and the return as cash flow $C F_{(\alpha, \beta)}$ of the ' $n$ ' stages has been calculated as follows. The selling price $=S P_{(\alpha, \beta)}$, operating expenses of mining, milling, and smelting and refining = $\Omega_{o}\left(M_{(\alpha, \beta)}, C_{(\alpha, \beta)}, R_{(\alpha, \beta)}\right)$, fixed costs of mining, milling, and smelting and refining $=\psi_{f}\left(M_{(\alpha, \beta)}, C_{(\alpha, \beta)}, R_{(\alpha, \beta)}\right)$, any 
other costs $=A C_{(\alpha, \beta)}$, tax rate $=T R_{(\alpha, \beta)}$ and depreciation $=D_{(\alpha, \beta)}$ of the mineral - all the elements are time indexed $(t)$ dependent variables, and the $C F_{(\alpha, \beta)}$ has been computed for the total life of mine $(n)$ as devised below in equation (43).

$$
\begin{aligned}
C F_{(\alpha, \beta)}= & \left\{S P_{(\alpha, \beta)} \times Q_{c(\alpha, \beta)} \times \overline{\mathrm{g}}_{(\alpha, \beta)} \times Y_{c_{(\alpha, \beta)}} \times Y_{r_{(\alpha, \beta)}}-\sum \Omega_{o}\left(M_{(\alpha, \beta)}, C_{(\alpha, \beta)}, R_{(\alpha, \beta)}\right)-\sum \psi_{f}\left(M_{(\alpha, \beta)}, C_{(\alpha, \beta),},\right.\right. \\
& \left.R_{(\alpha, \beta)}-A C_{(\alpha, \beta)}-D_{(\alpha, \beta)}\right\}\left(1-T R_{(\alpha, \beta))}\right)+D_{(\alpha, \beta)}
\end{aligned}
$$

The objective function is to maximize the $N P V$ for the total mineral deposit throughout the entire life of mine $(n)$. It is the cumulative summation of all the cash flows $\left(C F_{0}, C F_{1}, C F_{2} \ldots C F_{n}\right)$, where $C F_{0}$ is the capital invested having a fixed discount rate of ' $\partial$ ' up to $n^{\text {th }}$ year given by equation (44).

$N P V_{(\alpha, \beta)}(\operatorname{Max})=\frac{C F_{1}}{(1+\partial)}+\frac{C F_{2}}{(1+\partial)^{2}}+\cdots+\frac{C F_{n}}{(1+\partial)^{n}}-C F_{0}=\sum_{t=0}^{n} \frac{C F_{t}}{(1+\partial)^{t}}-C F_{0}$

Therefore, to get the maximum $N P V_{(\alpha, \beta)}$, sequential formulae for all the intermediate stages up to 'n' are derived using the generalized equation (45).

$$
\begin{aligned}
N P V_{(\alpha, \beta)}= & \operatorname{Max} \int_{t}^{n}\left[\left\{S_{(\alpha, \beta)} \times Q_{c(\alpha, \beta)} \times \overline{\mathrm{g}}_{(\alpha, \beta)} \times Y_{c_{(\alpha, \beta)}} \times Y_{r_{(\alpha, \beta)}}-\sum \Phi\left(M_{(\alpha, \beta)}, C_{(\alpha, \beta)}, R_{(\alpha, \beta)}\right)\right.\right. \\
\alpha \leq \mathbb{C} \leq \beta & \left.\left.-\sum \xi\left(M_{(\alpha, \beta)}, C_{(\alpha, \beta)}, R_{(\alpha, \beta)}-A C_{(\alpha, \beta)}-D_{(\alpha, \beta)}\right\}\left(1-T R_{(\alpha, \beta))}\right)+D_{(\alpha, \beta))}\right\} e^{-\partial t} d t\right]
\end{aligned}
$$

Using the equation (23), if one starts from stage one, all the intermediate states are evaluated stage by stage, until all the possible values of $N P V_{(\alpha, \beta)}$ are evaluated. Then, the maximum of $N P V_{(\alpha, \beta)}$ of all stages is chosen, so that the global maximum $N P V_{(\alpha, \beta)}$ correlating to a specific grade is the mill's global optimum COG. Here, the sequentially advancing algorithm has employed the memorization approach to identify the global COG in this case.

\subsection{Application and development of the computer-aided model}

A computer-aided COG-MDP model has been established for determining the optimal COG using the formulae mentioned - the proposed computational framework is derived from the multi-value dynamic programming approach for estimating the global optimum COG. The programming language used to develop the computer package is Python 3.7, the ideal multi-paradigm programming language for developing scientific and business applications. It imparts a great extent of calculation speed and data accuracy. Python have a logical set of dynamic binding rules with automatic memory guidance. It is compatible with various computing paradigms, such as structured, object-oriented, and functional and procedural programming. A $P y Q t$ framework, version-5, is used for this model. The COG-MDP model is divided into three sections: input, output, and graphical components. The Graphical User interface (GUI) has been developed using Python 3.7 and PyQt designer that comes with PyQt5 Library. In particular, there are some of the core packages like pandas, SciPy, NumPy and Matplotlib that has been used exclusively for this model. The automated model offers more operational capability and applicability. 
The ultimate optimum $C O G$ of the mineral grade and the optimized $N P V$ of the entire process is provided by the result module. The outputs of the result segment are separated into four segments: mine, mill, smelter and refinery, and earnings. The Result-graphical component, an essential element of the computer tool and GUI program, supports the logical conclusion. After the simulation, the computational framework displays the result as graphical data in various graphs between the provided variables. The user is presented with the following graphical displays by the tool: (1) Avg.Grade (\%) versus Tonnage(2)COG(\%) versus Cumulative Tonnage, Average Grade (\%) and (3) COG (\%) versus NPV.

\section{Corroboration of outputs using a working surface mining complex}

The work requires an actual case paper that describes a study of domain knowledge of an open-pit copper ore mine with all or at least three phases of ore production, namely extraction, concentration, and smelter and refinery, to evaluate the models. The model has been corroborated utilizing data from India's most extensive open-pit copper resources (surface mining complex).

\subsection{A brief description of the mining complex}

Malanjkhand Copper Project (MCP) is a subsidiary of Hindustan Copper Limited, which was commissioned on $12^{\text {th }}$ November 1982. The mining lease was approved in favor of HCL in 1973. The latitude and longitude of this mine are $22^{\circ} 00^{\prime} 59^{\prime \prime}$ to $22^{\circ} 02^{\prime} 24^{\prime \prime} N$ and $80^{\circ} 41^{\prime} 51^{\prime \prime}$ to $80^{\circ} 42^{\prime} 38^{\prime \prime} E$ and forms a part of Survey of India Toposheet No. 64 B/12, located in the Balaghat District of Madhya Pradesh in India. The strike length of the deposit is 2600 m. MCP, situated at a distance of $20 \mathrm{~km}$ away from the Kanha National Park, contributes about 80 percent of HCL's overall copper supply. This is the largest copper mine in India (Fig. 7), with an average orebody width of $75 \mathrm{~m}$. It has a total lease area of $479.9 \mathrm{ha}$.

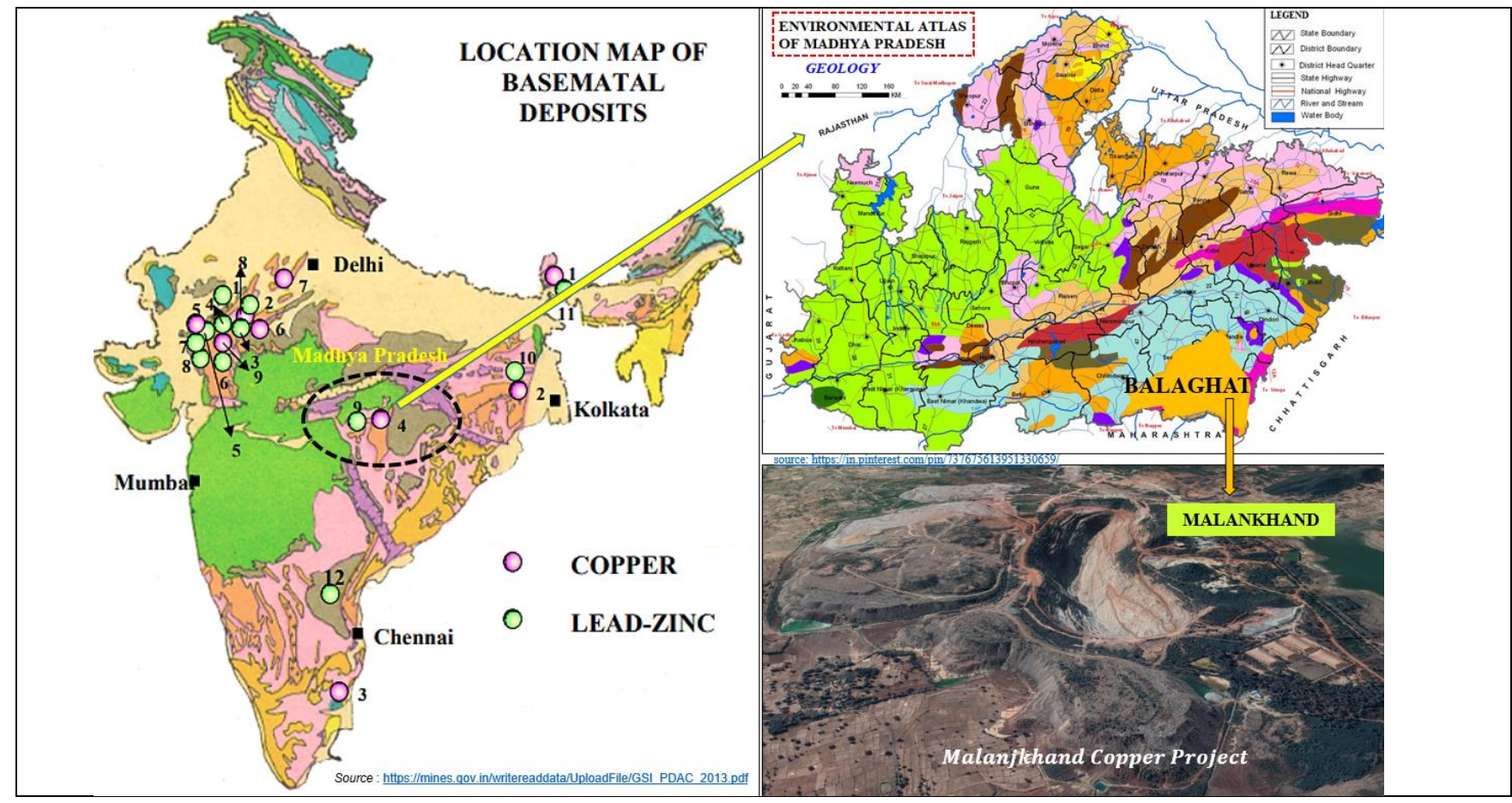

Fig. 7. Site location Map of Malanjkhand Copper Mine, HCL. 
Malanjkhand Copper Project is a massive metalliferous deposit amounting to 200 Million tonnes (Mt) of copper ore reserves. $\mathrm{MCP}$ has rich mineable copper reserves of $143 \mathrm{Mt}$, which is more than $70 \%$ of the country's available resources. India's largest copper mine, Malanjkhand deposit extends vertically from the surface at 580 mean reduced level $(m R L)$ to a depth of (-)300 mRL. Open-pit mining was planned initially to a depth of $204 \mathrm{~m}$ (376 $\mathrm{mRL}$ ), which is now extended to $240 \mathrm{~m}(340 \mathrm{mRL})$. Below the open-pit floor, there exist $160 \mathrm{Mt}$ reserves of $1.34 \%$ copper grade containing over two million tonnes of copper metal. At present, the central portion of the deposit is being mined out by the open cast mining method, which has reached the Ultimate Pit Limit (UPL).

The general area in the vicinity of the mine is a hilly terrain consisting of narrow basins and hills. Malanjkhand rises in isolated majesty above the undulating terrain and forms a part of the Baihar Plateau. Six peaks with intervening saddles are observed that create an arcuate chain of about $2.6 \mathrm{~km}$ long, having an eastward convexity. This highest peak is about $652 \mathrm{~m}$ above mean sea level $(\mathrm{mSL})$, while the ground level of the surrounding area is around 575 above $m S L$. This describes the general elevation of the Baihar Plateau, which rises about $270 \mathrm{~m}$ above the Balaghat Plains. The digital surface contour terrain of the above area within lease boundary and the surface plan of the project is shown is Fig. 8 (a) and (b).

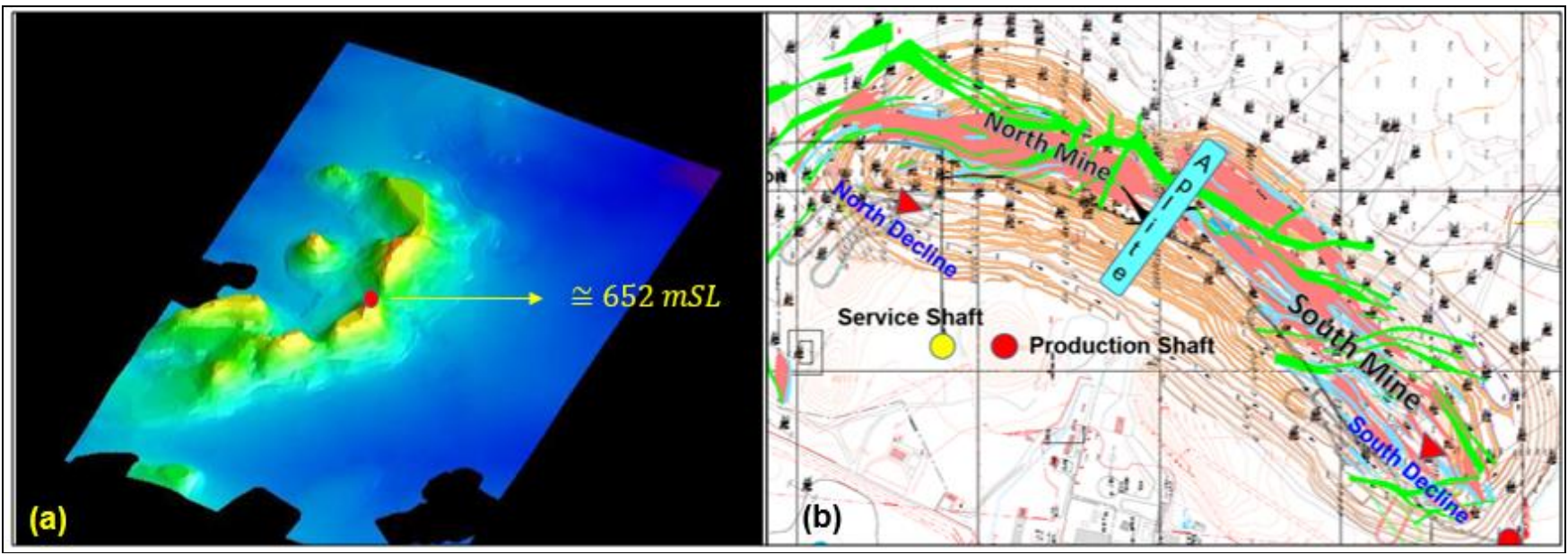

Fig. 8. (a) Initial Surface Contour Terrain (source: HCL) (b) Surface Plan of Malanjkhand Copper Mine (source: HCL)

King (W. King, 1886) initially noted the presence of copper in Malanjkhand in 1886, and Dunn reported it in 1942 (Dunna, 1942). Later, the porphyry character of the copper deposit was discovered by Sikka in 1971, opening up new possibilities in the search for the substantial tonnage of Precambrian polymetallic porphyry copper deposits in Madhya Pradesh, India (Sikka \& Nehru, 1997). The Geological Survey of India (GSI) carried out systematic geological mapping at this site in 1969. Malanjkhand Copper belt consists of a large body of copper ore in granite rocks, ranging in composition from diorite to granite. The rocks of Malanjkhand are from the Proterozoic era and can be divided into two groups, each with unique attributes, distinguished by an unconformity. The oldest group, composed of basement rocks, was formed first, followed by the younger, less metamorphosed rocks of the Chilpi Ghat beds. Three distinct forms of mineralization are clearly visible. Firstly, the mineralization is primarily 
correlated with quartz, which is generally limited to the quartz reef as a fracture fill form and can be known as quartz ore. Secondly, the mineralization of the stringer pattern has quartz and calcite joints. This stringer ore is found primarily in granites. Lastly, the disseminated ore inside granites or micro granites is present within the interstices of inherent grains of the related rocks. The most predominant ores are chalcopyrite, chalcocite, and malachite in order of abundance. The secondary and oxidized ore minerals are confined to the upper part of the deposit. Due to hydrothermal vein formation, the Malanjkhand copper ore deposit geometry varies in the strike and dip directions. The host rock is quartz reef and granite.

Surface mining (open-pit) will be continued for exploiting the deposit. As per the revised mine plan schedule, mining is contemplated to expand the pit to a depth of $340 \mathrm{mRL}$. A view of the working pit and the modelled Ultimate Pit design of the Malanjkhand Copper Project is shown in Fig. 9 (a) and (b).
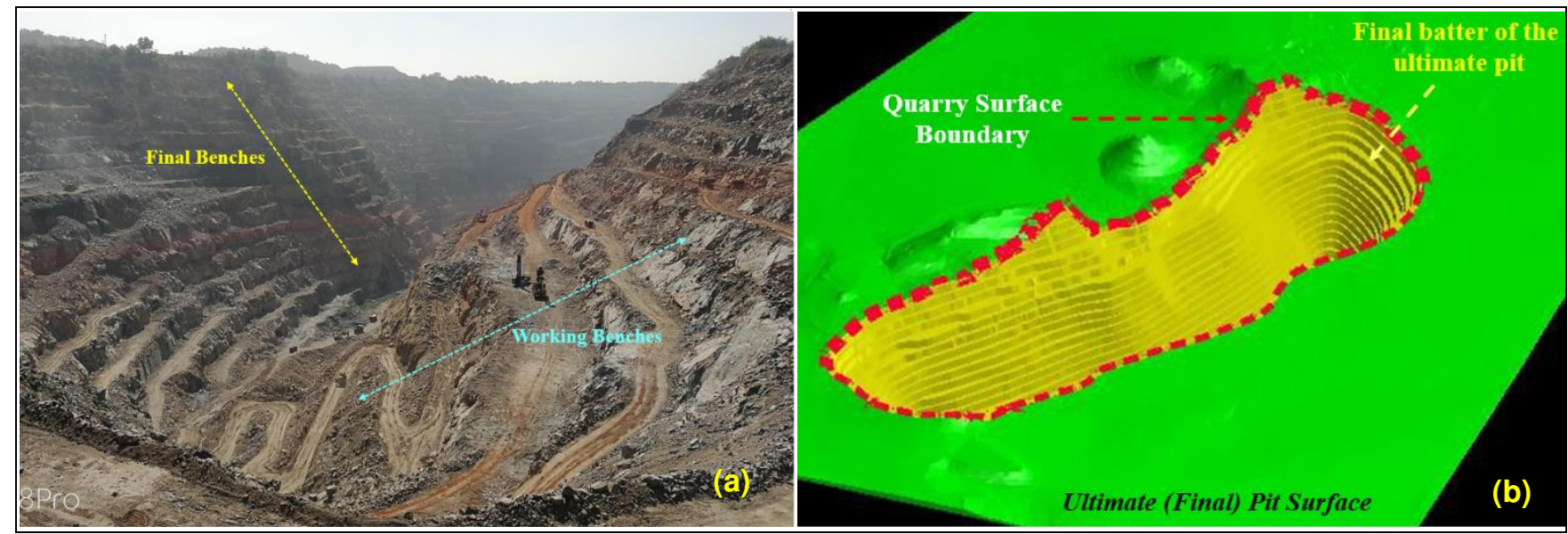

Fig. 9 (a) Working Pit of Malanjkhand Copper Project (b) Ultimate Pit design based on 3-D mine planning software (source: HCL)

The computations are made using the grade-tonnage variance and operating variables (mine, mill, and refinery capacities). Economic values have been assessed in accordance with the Indian context (in ₹). Table 2 shows the mineral content inside the grade bins.

Table 2 Grade-tonnage variance of the copper deposit.

\begin{tabular}{ccc}
\hline Grade $\boldsymbol{f r o m}(\% \boldsymbol{C u})$ & Grade to $(\% \boldsymbol{C u})$ & Tonnage $($ in tonnes $)$ \\
\hline 0.20 & 0.45 & 25909429 \\
0.45 & 0.50 & 3292995 \\
0.50 & 0.60 & 6222261 \\
0.60 & 0.70 & 6917390 \\
0.70 & 0.80 & 6538756 \\
0.80 & 0.90 & 5674345 \\
0.90 & 1.00 & 3501976 \\
1.00 & 1.10 & 3331731 \\
1.10 & 1.20 & 3283519 \\
1.20 & 1.30 & 2360291 \\
1.30 & 1.40 & 1816110 \\
1.40 & 1.50 & 1638172 \\
1.50 & 5.60 & 9154230 \\
\hline
\end{tabular}




\subsection{Model-inputs}

Geo-mining details and techno-economic variables are the vital input parameters for optimizing the objective function for maximization of $N P V$. The essential techno-economical parameters used for the COG-MDP model is shown in Table 3. The following data has been used as input data to determine global optimum COG\%. This data will be imported into the $C O G-N P V$ optimizer tool for the calculation and software input.

Table 3 Techno-economical parameters used for the surface mining complex in Indian currency (rupees-₹).

\begin{tabular}{|c|c|}
\hline \multicolumn{2}{|l|}{ Mining } \\
\hline Particulars & Values \\
\hline Maximum mining capacity (tonnes / yr) & 2540000 \\
\hline Percentage mining recovery $(\%)$ & 100 \\
\hline Specific investment cost for mining (₹/ tonne / yr) & 160 \\
\hline Unit cost of excavation (₹ / tonne ore \& waste) & 816.91 \\
\hline Fixed mining cost (₹ / tonne) & 28026.48 \\
\hline Average ore transportation cost (₹ / tonne / km) & 43.30 \\
\hline Average waste transportation cost (₹ / tonne / km) & 43.30 \\
\hline Average ore transportation haul distance $(\mathrm{km})$ & 6 \\
\hline Average waste transportation haul distance $(\mathrm{km})$ & 6 \\
\hline \multicolumn{2}{|l|}{ 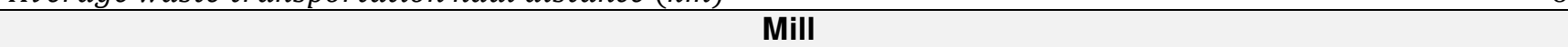 } \\
\hline Maximum mill capacity (tonnes / yr) & 2340000 \\
\hline Mill concentrate grade $(\%)$ & 26 \\
\hline Percentage mill Recovery (\%) & 92.5 \\
\hline Specific investment cost for mill (₹ / tonne / yr) & 150 \\
\hline Unit cost of ore processing (₹ / tonne) & 464.42 \\
\hline Fixed mill cost $(₹ /$ tonne $)$ & 29314.02 \\
\hline Average concentrate transportation cost (₹/ tonne / $\mathrm{km}$ ) & 1.95 \\
\hline Average mill tailing transportation cost (₹/ tonne / km) & 3 \\
\hline Average concentrate transportation haul distance $(\mathrm{km})$ & 180 \\
\hline Average mill tailing transportation haul distance $(\mathrm{km})$ & 4.6 \\
\hline \multicolumn{2}{|l|}{ Refinery } \\
\hline Maximum refinery capacity (tonnes / yr) & 18500 \\
\hline Percentage refinery Recovery (\%) & 99.66 \\
\hline Specific investment cost for refinery (₹ / tonne / yr) & 500 \\
\hline Unit cost of refining (₹ / tonne of metal produced) & 57600 \\
\hline Fixed refinery cost (₹ / tonne) & 47800 \\
\hline Average metal transportation cost (₹ / tonne / $\mathrm{km}$ ) & 3 \\
\hline Average slag transportation cost (₹ / tonne / km) & 3 \\
\hline Average metal transportation haul distance $(\mathrm{km})$ & 0.5 \\
\hline Average slag transportation haul distance $(\mathrm{km})$ & 0.5 \\
\hline \multicolumn{2}{|l|}{ Additional Costs } \\
\hline $\begin{array}{l}\text { Other costs including general administration cost } \\
\text { (percentage } \% \text { of the total operating cost) }\end{array}$ & 25 \\
\hline \multicolumn{2}{|l|}{ Rates } \\
\hline Selling price of metal (₹ / tonne) & 500000 \\
\hline Tax rate $(\%)$ & 34 \\
\hline Discount rate (\%) & 11 \\
\hline \multicolumn{2}{|c|}{ Grade Interval Precision } \\
\hline Grade Interval increment (\%) & 0.01 \\
\hline
\end{tabular}




\title{
4.3 Result-outputs
}

The data has been loaded into the program and analyzed by the COG-MDP model, and the final optimized output for each component was obtained and shown in Table 4.

Table 4 Summary of the results output of all the eight modules.

\begin{abstract}
Abbreviation used for the output variables:
$\mathbf{O C O G}=$ Optimum mill COG \% ; $\mathbf{T}\left(\boldsymbol{T}_{\boldsymbol{o}}\right)(t)=$ Total tonnage of ore production (tonnes); $\boldsymbol{S}_{\boldsymbol{\alpha}, \boldsymbol{\beta}}=$ Overall Stripping ratio; $\boldsymbol{C}_{\boldsymbol{n}}(t / y r)=$ Tonnage of concentrate produced per year; $\boldsymbol{T}_{\boldsymbol{l}}(t / y r)=$ Tonnage of mill tailing produced per yr;

$\boldsymbol{T}\left(\boldsymbol{C}_{\boldsymbol{n}}\right)(t)=$ Total tonnage of concentrate produced; $\boldsymbol{T}\left(\boldsymbol{T}_{l}\right)(t)=$ Total tonnage of mill tailing produced;

$\boldsymbol{S}_{\boldsymbol{g}}(t / y r)=$ Tonnage of slag produced per year; $\mathrm{T}\left(\boldsymbol{Q}_{\boldsymbol{r}}\right)(t)=$ Total tonnage of metal produced; $\overline{\mathrm{g}}=$ Average head grade $\%$ $\mathrm{T}\left(\boldsymbol{S}_{\boldsymbol{g}}\right)(t)=$ Total tonnage of slag produced; $\mathbf{T}\left(\boldsymbol{C F}_{\boldsymbol{o}}\right)(₹)=$ Total Investment $; \boldsymbol{D}_{\boldsymbol{p}}(₹ /$ yr $)=$ Depreciation;

$\boldsymbol{R}_{\boldsymbol{v}}(₹ / y r)=$ Revenue generated per yr; $\boldsymbol{A O M C}(₹ /$ yr $)=$ Annual operating and maintenance cost ;

$\boldsymbol{G P}(₹ / y r)=$ Gross profit per yr; $\boldsymbol{N}_{\boldsymbol{p}}(₹)=$ Net profit per $y r ; \mathbf{T}\left(\boldsymbol{N}_{\boldsymbol{p}}\right)(₹)=$ Total Net profit; $\boldsymbol{C F}_{\boldsymbol{y}}(₹)=$ Annual cash-flow; $\boldsymbol{A C}(₹ / y r)=$ Annual other costs including GAC \& fixed cost; $\mathbf{T}\left(\boldsymbol{R}_{\boldsymbol{v}}\right)(₹)=$ Total Revenue generated
\end{abstract}

\begin{tabular}{|c|c|c|c|c|c|c|c|c|}
\hline Modules & $M-1 / 4 / 6$ & M-2 & M-3 & M-5 & M-7 & M-8A & M-8B & M-8C \\
\hline Particulars & values & values & values & values & values & values & values & values \\
\hline \multicolumn{9}{|c|}{ Mining (production in tonnes $(t))$} \\
\hline $\boldsymbol{Q}_{\boldsymbol{m}}(t / y r)$ & 2132818 & 2540000 & 3788250 & 2538177 & 2132818 & 4191642 & 5680398 & 26547068 \\
\hline OCOG (\%) & 0.33 & 0.23 & 0.52 & 0.26 & 0.33 & 0.27 & 0.22 & 0.24 \\
\hline Life $(y r s)$ & 38.00 & 32.00 & 22.00 & 32.00 & 38.00 & 19.00 & 15.00 & 3.00 \\
\hline $\mathbf{T}\left(\boldsymbol{T}_{o}\right)(t)$ & 66168302 & 76532073 & 49194329 & 73422942 & 66168302 & 72386565 & 77568451 & 75495696 \\
\hline $\mathbf{T}\left(\boldsymbol{T}_{\boldsymbol{w}}\right)(t)$ & 13472903 & 3109131 & 30446876 & 6218263 & 13472903 & 7254640 & 2072754 & 4145509 \\
\hline$S_{\alpha, \beta}$ & 0.20 & 0.04 & 0.62 & 0.08 & 0.20 & 0.10 & 0.03 & 0.05 \\
\hline \multicolumn{9}{|c|}{ Mill (production in tonnes $(t)$ ) } \\
\hline $\boldsymbol{Q}_{c}(t / y r)$ & 1772009 & 2440840 & 2340000 & 2340000 & 1772009 & 3809819 & 5532559 & 25165232 \\
\hline$\overline{\mathrm{g}}(\%)$ & 1.133 & 1.017 & 1.380 & 1.050 & 1.133 & 1.061 & 1.006 & 1.028 \\
\hline $\boldsymbol{C}_{\boldsymbol{n}}(t / y r)$ & 71397 & 88320 & 114884 & 87393 & 71397 & 143809 & 198108 & 920194 \\
\hline $\boldsymbol{T}_{l}(t / y r)$ & 1700613 & 2352521 & 2225116 & 2252607 & 1700613 & 3666010 & 5334452 & 24245038 \\
\hline $\boldsymbol{T}\left(\boldsymbol{C}_{\boldsymbol{n}}\right)(t)$ & 2713071 & 2826231 & 2527440 & 2796564 & 2713071 & 2732376 & 2971619 & 2760583 \\
\hline $\boldsymbol{T}\left(\boldsymbol{T}_{l}\right)(t)$ & 64623286 & 75280661 & 48952560 & 72083436 & 64623286 & 69654189 & 80016774 & 72735114 \\
\hline \multicolumn{9}{|c|}{ Smelter/Refinery (production in tonnes $(t))$} \\
\hline $\boldsymbol{Q}_{r}(t / y r)$ & 18500 & 22885 & 29768 & 22645 & 18500 & 37263 & 51333 & 238437 \\
\hline $\boldsymbol{S}_{\boldsymbol{g}}(t / y r)$ & 52897 & 65435 & 85115 & 64748 & 52897 & 106546 & 146775 & 681757 \\
\hline $\mathbf{T}\left(\boldsymbol{Q}_{r}\right)(t)$ & 703000 & 732322 & 654900 & 724635 & 703000 & 708002 & 769994 & 715311 \\
\hline $\mathbf{T}\left(\boldsymbol{S}_{\boldsymbol{g}}\right)(t)$ & 2010071 & 2093909 & 1872540 & 2071930 & 2010071 & 2024374 & 2201625 & 2045271 \\
\hline \multicolumn{9}{|c|}{ Profits (₹ in million) } \\
\hline $\mathbf{T}\left(\boldsymbol{C I} \boldsymbol{I}_{o}\right)(₹)$ & 616 & 784 & 972 & 768 & 616 & 1261 & 1764 & 8142 \\
\hline $\boldsymbol{D}_{p}(₹ / y r)$ & 16 & 24 & 44 & 24 & 16 & 66 & 118 & 2714 \\
\hline $\boldsymbol{R}_{v}(₹ / y r)$ & 9250 & 11443 & 14884 & 11322 & 9250 & 18632 & 25666 & 119219 \\
\hline $\operatorname{AOMC}(₹ / y r)$ & 4232 & 5250 & 6935 & 5185 & 4232 & 8530 & 11783 & 54664 \\
\hline $\boldsymbol{A C}(₹ / y r)$ & 2848 & 3538 & 4651 & 3493 & 2848 & 5745 & 7943 & 36835 \\
\hline $\boldsymbol{G P}(₹ / y r)$ & 2154 & 2630 & 3254 & 2621 & 2154 & 4290 & 5823 & 25006 \\
\hline $\operatorname{Tax}(₹ / y r)$ & 732 & 894 & 1106 & 891 & 732 & 1458 & 1980 & 8502 \\
\hline $\boldsymbol{N}_{p}(₹ / y r)$ & 1422 & 1736 & 2148 & 1730 & 1422 & 2831 & 3843 & 16504 \\
\hline $\boldsymbol{C F}_{\boldsymbol{y}}(₹ / y r)$ & 1438 & 1760 & 2192 & 1754 & 1438 & 2898 & 3961 & 19218 \\
\hline$N P V$ (₹) & 12208 & 14653 & 16948 & 14609 & 12208 & 21454 & 26717 & 38821 \\
\hline $\mathbf{T}\left(\boldsymbol{R}_{v}\right)(₹)$ & 351500 & 366161 & 327450 & 362317 & 351500 & 354001 & 384997 & 357656 \\
\hline $\mathrm{T}\left(N_{p}\right)(₹)$ & 54026 & 55552 & 47248 & 55350 & 54026 & 53792 & 57647 & 49511 \\
\hline
\end{tabular}

In this model, the input values (operational and economical) have been taken irrespective of the time. Therefore, the values and results will behave accordingly as per the user's input values. Thus, the mine planners or experts 
will run their module as per the current situation and get their results to optimize accordingly. If there will be a significant increase in the pricing dynamics in the coming years, the planning experts will run through the program and optimize accordingly. Therefore, there is no need to introduce the price forecasting technique in this model because there are a host of variables where the cost-escalation factor will be applicable, including the entire mine, mill, and smelter and refinery stages. Therefore, considering all the variables will make things more complex and may lead to an indefinite solution.

\subsection{Graphical interface-result module}

The graphical user interface of the result module for the above-described outputs is represented in various graphs through Figures 10, 11, 12, and 13, respectively.

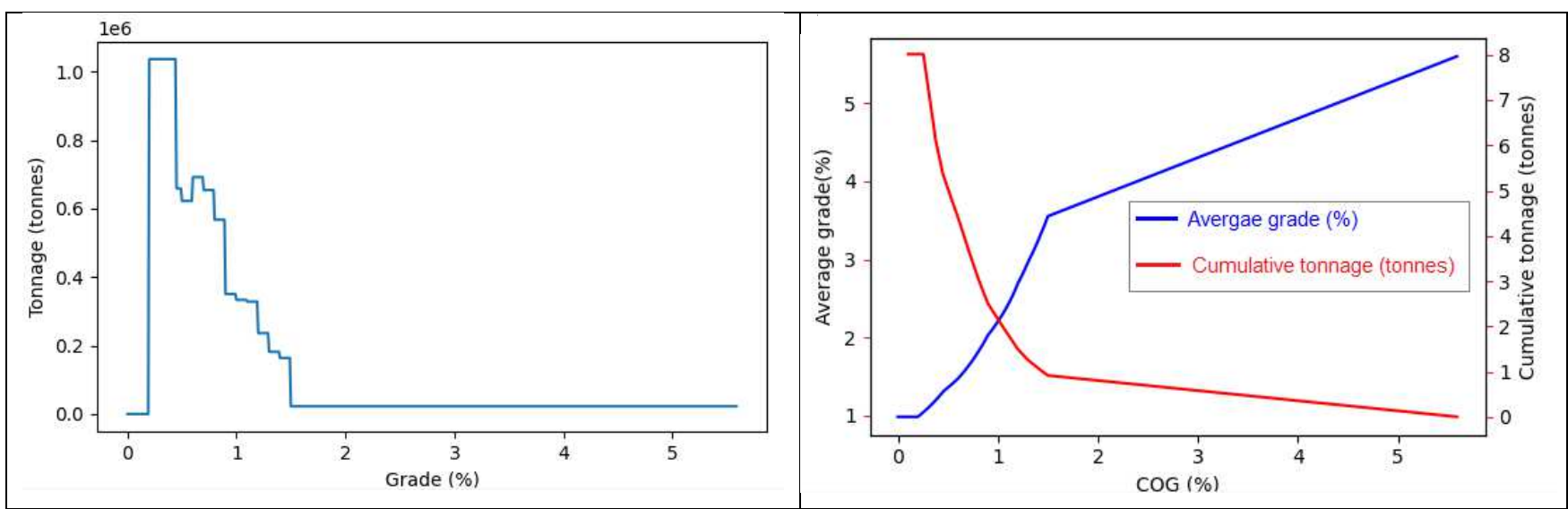

Fig. 10. (a) Tonnage versus Grade distribution of deposit (b) Cumulative tonnage, Average grade versus COG

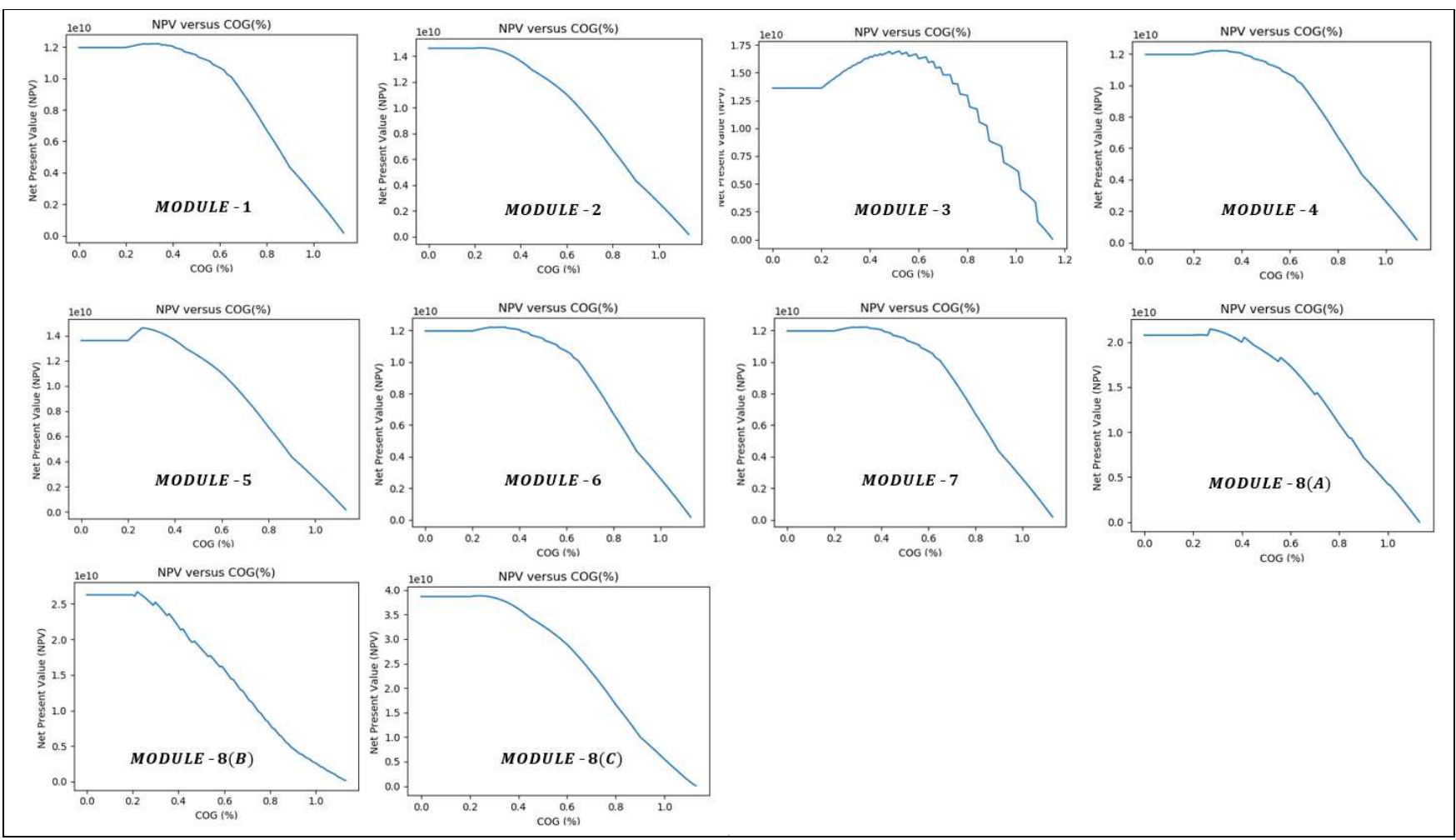

Fig. 11. Showing all the $N P V$ values versus $C O G(\%)$ related with the eight modules. 


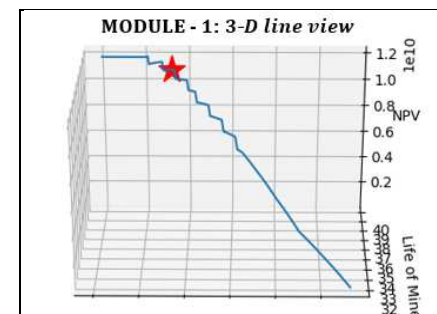

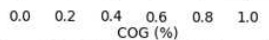
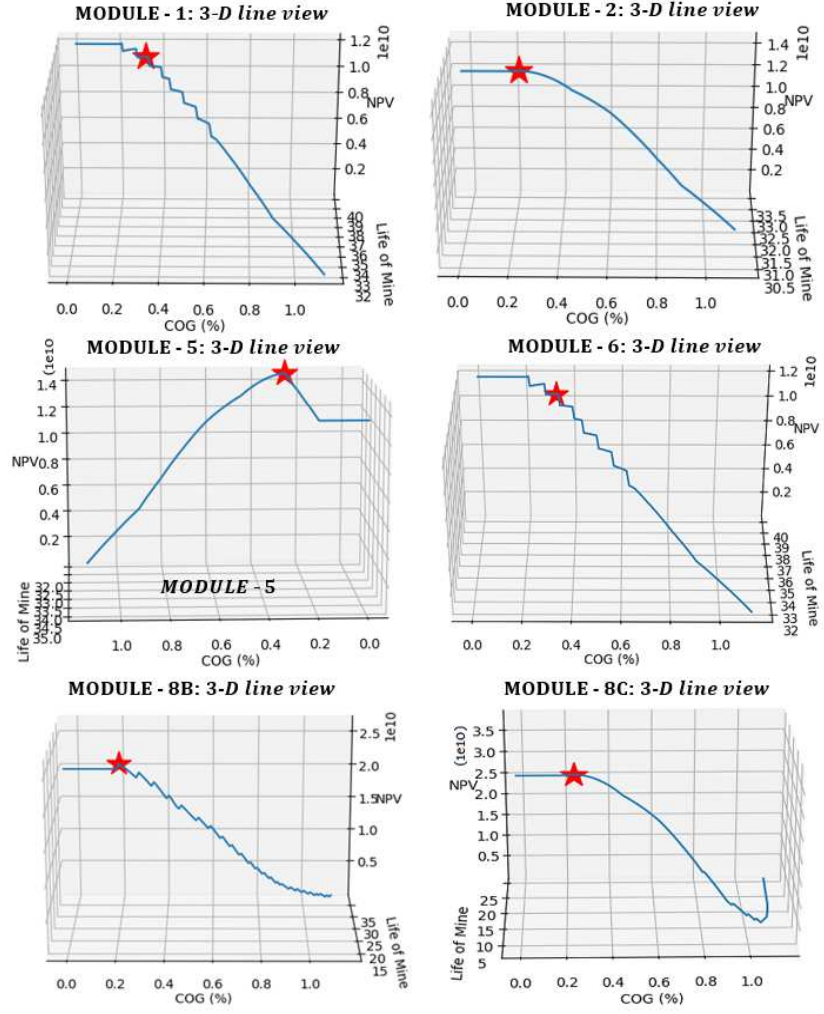
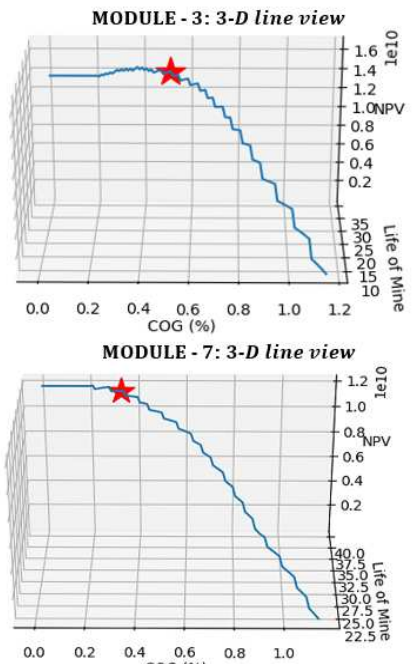

$\begin{array}{llllll}0.0 & 0.2 & 0.4 & 0.6 & 0.8 & 0.0\end{array}$

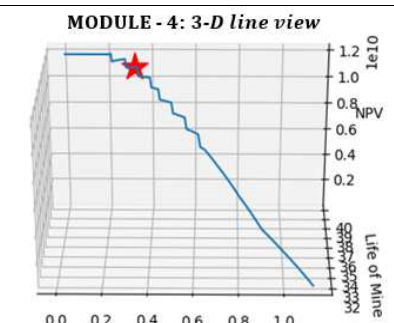

$\begin{array}{llllll}0.0 & 0.2 & 0.4 & 0.6 & 0.8 & 1.0 \\ \operatorname{Cog}(\%) & & \end{array}$ MODULE - 8A: 3-D line view

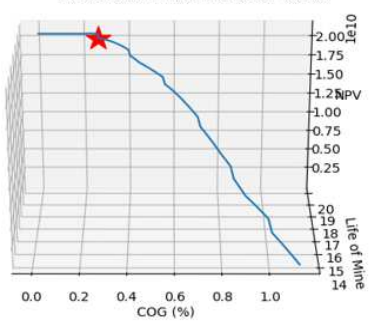

Fig. 12. Showing the $3-D$ line graph of $N P V$ s versus $C O G(\%)$ versus life of mine of all the eight modules.

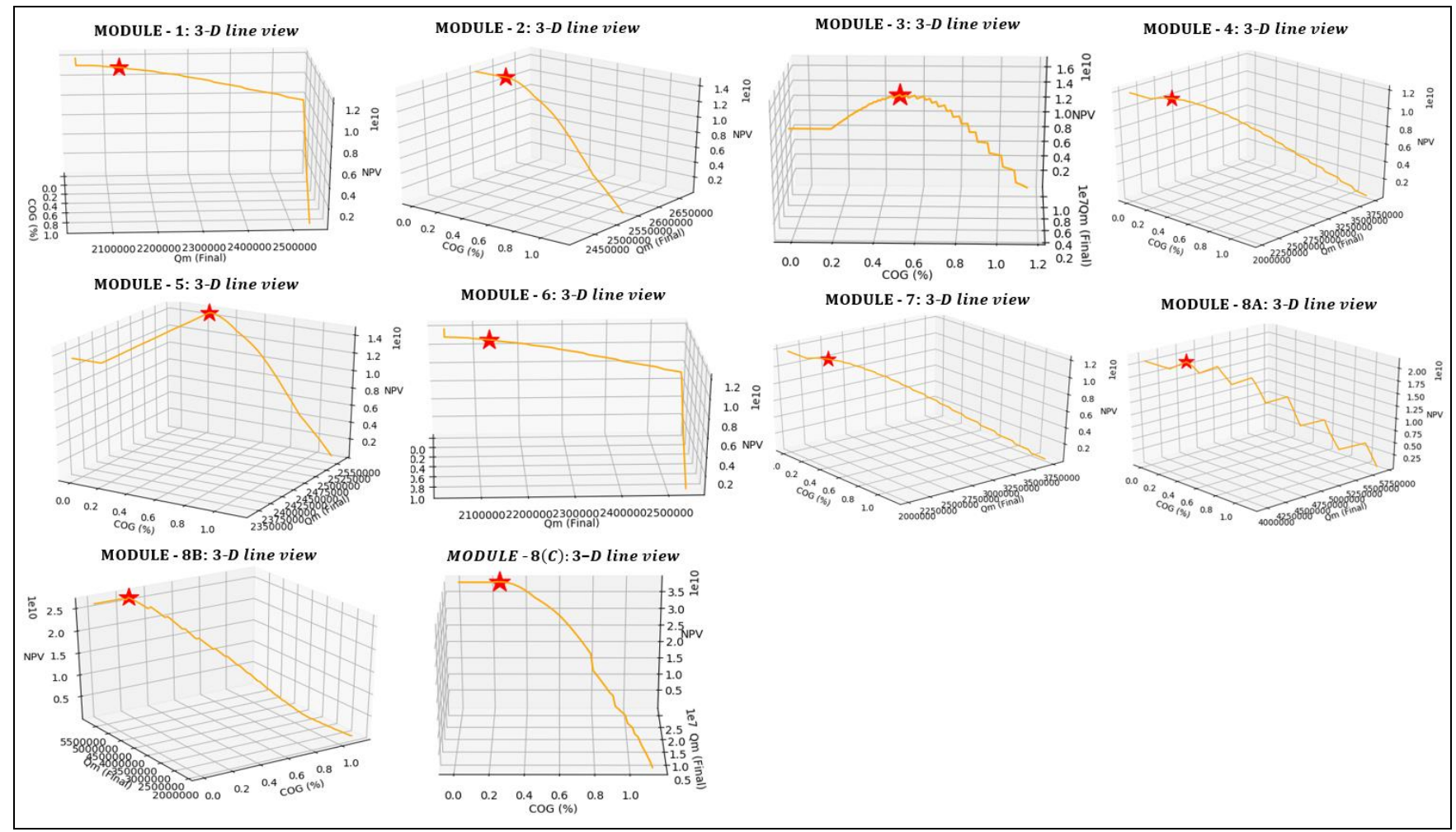

Fig. 13. Showing the $3-D$ line graph of $N P V$ s versus $C O G(\%)$ versus mine production $\left(Q_{m}\right)$ of all the eight modules. 


\section{Discussions of results}

The results after the simulation from all the eight modules have been presented through tables and figures. The observations according to the given grade-tonnage and techno-economic variations are discussed below in Table 5.

Table 5 Conclusive summary sheet of the output variables of all the eight modules for the open-pit metalliferous deposit (MCP).

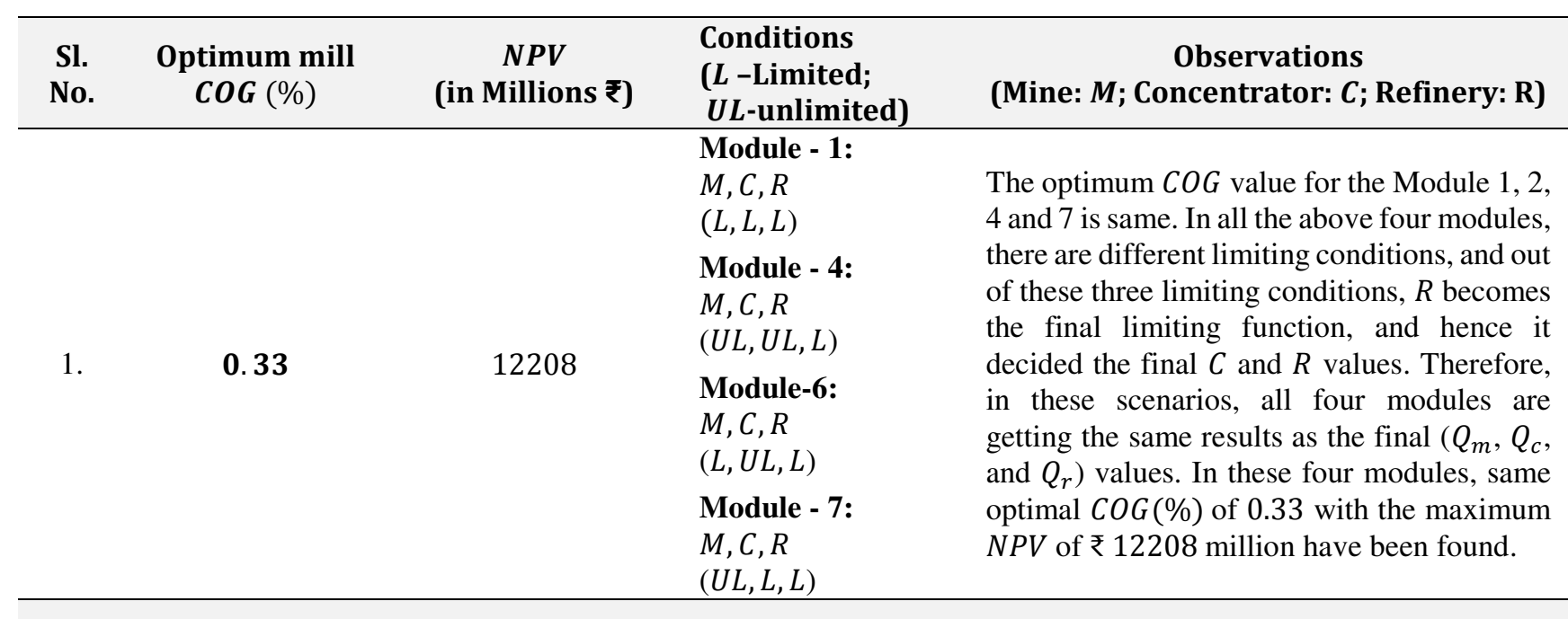

In Module 2, $M$ is the limiting function. It
2.
0.23
14653
Module - 2:
$M, C, R$
$(L, U L, U L)$ correspondingly, the limiting logical conditions on $\mathrm{M}, \mathrm{C}$, and $\mathrm{R}$ values contributed to the final $\left(Q_{m}, Q_{c}\right.$, and $\left.Q_{r}\right)$ results. This module has given the optimal $\operatorname{COG}(\%)$ at 0.23 with the maximum NPV of ₹ 14653 million.

In Module 3, $\mathrm{C}$ is the limiting function. It has decided the ultimate $\mathrm{M}$ and $\mathrm{R}$ values, and correspondingly the limiting logical conditions on $\mathrm{M}, \mathrm{C}$, and $\mathrm{R}$ values contributed to the final $\left(Q_{m}, Q_{c}\right.$, and $\left.Q_{r}\right)$ results. This module has given the optimal $\operatorname{COG}(\%)$ at 0.52 with the maximum NPV of ₹ 16947 million.

In Module 5, $\mathrm{M}$ and $\mathrm{C}$ are the limiting function, whereas $\mathrm{R}$ has a scope of unlimited capacity. So, limiting conditions of $\mathrm{M}$ and $\mathrm{C}$ have decided the ultimate values, and correspondingly the limiting logical conditions on $\mathrm{M}, \mathrm{C}$, and $\mathrm{R}$ values contributed to the final $\left(Q_{m}, Q_{c}\right.$, and $\left.Q_{r}\right)$ values. This module has given the optimal $\operatorname{COG}(\%)$ at 0.26 with the maximum NPV of ₹ 14609 million. 
Module -8 (A):

Taylor (Taylor, 1986)

$M, C, R$

$(U L, U L, U L)$

MM

0.22

26717

Module - 8 (B):

Long (Long, 2009)

$M, C, R$

$(U L, U L, U L)$

\begin{tabular}{|c|c|c|}
\hline \multirow{2}{*}{\multicolumn{3}{|c|}{ Module - 8 (C): }} \\
\hline & & \\
\hline 0.24 & 38821 & $\begin{array}{l}\text { DP based algorithm } \\
\text { (COG-MDP model }\end{array}$ \\
\hline & & $\begin{array}{l}\text { described in the } \\
\text { paper) } M, C, R \\
(U L, U L, U L)\end{array}$ \\
\hline
\end{tabular}

Module - 8 (C): DP based algorithm (COG-MDP model described in the $(U L, U L, U L)$
Module 8(A)/ 8(B)/ 8(C)

When all the capacities (mining, concentrator, and smelter and refinery) are unlimited, the optimal $\operatorname{COG}(\%)$ and the corresponding maximum $N P V$, mine production and mine life have been calculated according to Taylor's (Taylor, 1986) mine life rule, by Long's (Long, 2009) rule and by the DP based algorithm (the presented COG$M D P$ model). It has been found that in all the three cases, mining capacity becomes the limiting function. Therefore, the logic sequentially advances and decides the final $C$ and $R$ values, and correspondingly the limiting logical conditions on $Q_{c}$ and $Q_{r}$ values will contribute to the final results. It may be observed that among the three methods for the unlimited conditions, the DP based algorithm gives the maximum NPV of ₹ 388201 million at COG(\%) of 0.24 .

A major advantage of the DP based algorithm is that it optimizes all the four variables COG\%, NPV , mine production and mine life simultaneously.

It may be observed that the results obtained from all the different modules using the real life data behave dynamically as per the existing grade-tonnage, techno-economic criteria, and other limiting conditions.

\section{Conclusion and recommendations}

The significance of developing a new evaluation technique, such as the one proposed in this study, lies in providing a pragmatic analytical approach to the mining industry that allows the mine planner or analyst to obtain a more realistic estimate of an open-pit project value accounts for the given techno-economic conditions. The three primary stages utilized in $C O G$ optimization depend upon the limiting conditions of mining, milling, and smelting and refining. In each of these sectors, several smaller divisions may be established. By individually optimizing mine and $C O G$ in planning stages, a guarantee of obtaining the highest $N P V$ is generally lost.

This necessitates developing a suitable approach for finding the optimum COG of ore, and hence a multi-value dynamic programming has been developed and used to compute $C O G$ for a metalliferous deposit. In this model, discrete values have been utilized for Dynamic Programming $(D P)$, a more deterministic approach than stochastic one. The developed model is based on the concept of dynamic programming and thus finds the solution much more straightforward than other optimization techniques. The fundamental framework and dynamics guide this model rather than tailoring it to time series. This increases the model's generic validation, but it takes a long time to design and parameterize. Its key strength is that it optimizes several policies simultaneously, that the results are connected 
and mutually reliable, and effectively validates against facts. As in this model, COG optimization has been carried out after finalizing the Ultimate Pit, and the pit optimization follows the objective function of maximizing profits irrespective of time. Therefore, whenever one does mining, it will create wealth, and the economics will behave as per the existing scenario. As a result, mine planners must re-run the $C O G-M D P$ optimizer model depending on market conditions and modify their intermediate stages of excavation following demand and economics. In general, the mine planners can choose their optimization in three stages.

- First stage by initially excavating higher-grade ore to recover capital, operating, and running costs and reduce the payback period.

- Second stage, by recovering the depreciation and tax amounts, can mine with the average-grade or lower grade.

- Third stage, when the machines or plants are fully depreciated, they can go for mining the lower grade ore and sustain the working of mines.

This work has the novelty of dealing with eight different optimization possibilities. So far, only six potential outcomes have been dealt with as on date by Lane (Lane, 1964). The computer can produce the result in seconds from the complex system of mine, mill, and smelter and refinery comprising of eight different possibilities. Thus, it will be a useful industry-oriented tool to plan a mining project for a given deposit considering all the possible dynamic conditions. An alternate way to Lane's algorithm and other current methodologies, based on mathematical programming, is described here as a practical and generic method for determining optimal COG, production rate, mine-life and the global $N P V$.

The Malanjkhand copper complex, for example, faces a variety of production restrictions. Besides, these operations will generally have a well-defined operating range, which may vary in actual situations. The model ignores the volatility and variations in economic characteristics, such as commodity pricing, stockpiling, dilution, multimineral aspects, and mine-restoration. The stockpiling option has not been included as that may increase the complexities enormously and lead to an incomplete solution. The objective of this model is to introduce a universal approach for resolving the optimality scenario related to $C O G$ of open-pit metalliferous deposits.

This optimization framework methodology can handle technically more acceptable relations, functions, and multidynamic aspects. However, the software provides enough flexibility to include or exclude the parameter(s) by changing the design's code; therefore, there is ample room for the expansion and modification of the model to cover additional scenarios. The intention here is to introduce a general method for the solution with a deterministic mathematical approach.

However, there is a scope to modify the program by including the stochastic behavior of the variables (commodity price, operating and maintenance expenses, fixed cost, discount rate etc.) to make it more applicable but at the cost of increasing the complexities. Though, in the future, if there is a significant increase in the price dynamics, the planning experts will run through the program and optimize accordingly. However, based on mining conditions 
and economics, the material categorized as waste could become economically viable to process in the future, necessitating a shift in policy. So, the utility and complexity of stockpiling is a more extensive area to explore.

\section{Acknowledgements}

"The authors are thankful to the management of Hindustan Copper Limited, Malanjkhand, for providing logistical support and necessary data for carrying out the study".

This work is a part of the first author's ongoing doctoral research. The help given by concerned individuals from various departments of Indian Institute of technology (Indian School of Mines), Dhanbad is much appreciated. "The writers' opinions in this work are their own, not necessarily those of the organisations to which they belong".

\section{References}

Ahmadi, M. R. (2018). Cutoff grade optimization based on maximizing net present value using a computer model. Journal of Sustainable Mining, 17, 68-75. https://doi.org/10.1016/j.jsm.2018.04.002

Ahmadi, M. R., \& Shahabi, R. S. (2018). Cutoff grade optimization in open pit mines using genetic algorithm. Resources Policy, 55, 184-191. https://doi.org/10.1016/j.resourpol.2017.11.016

Ali, A., Danish, K., Khan, A., Muhammad, K., Ahmad, W., \& Salman, S. (2021). A simulated annealing based approach for open pit mine production scheduling with stockpiling option. Resources Policy, 71(February), 1-11. https://doi.org/10.1016/j.resourpol.2021.102016

Asad, M. W. A. (2005). Cutoff grade optimization algorithm with stockpiling option for open pit mining operations of two economic minerals. International Journal of Surface Mining, Reclamation and Environment, 19(3), 176-187. https://doi.org/10.1080/13895260500258661

Asad, M. W. A., \& Topal, E. (2011). Net present value maximization model for optimum cut-off grade policy of open pit mining operations. Journal of the Southern African Institute of Mining and Metallurgy, 111(11), 741-750.

Azimi, Y., Osanloo, M., \& Esfahanipour, A. (2012). Selection of the open pit mining cut-off grade strategy under price uncertainty using a risk based multi-criteria ranking system. Archives of Mining Sciences, No 3, 189212. https://doi.org/10.2478/v10267-012-0048-8

Baidowi, N., Rosyidi, C. N., \& Aisyati, A. (2021). A Cut-Off Grade Optimization Model in Open Pit Mining Considering Reclamation Cost and Revenue. In Proceedings of IOP Conference Series: Materials Science and Engineering, 1096(1), 1-8. https://doi.org/10.1088/1757-899x/1096/1/012021

Bascetin, A., \& Nieto, A. (2007). Determination of optimal cut-off grade policy to optimize NPV using a new approach with optimization factor. The Journal of The Southern African Institute of Mining and Metallurgy, 107, 87-94.

Bellman, R. (1972). The structure of dynamic programming processes (Dynamic Pr). Princeton University Press.

Biswas, P., Sinha, R. K., Sen, P., \& Rajpurohit, S. S. (2020). Determination of optimum cut-off grade of an openpit metalliferous deposit under various limiting conditions using a linearly advancing algorithm derived from dynamic programming. Resources Policy, 66, 1-11. https://doi.org/10.1016/j.resourpol.2020.101594

Chanda, E. K. C., \& Dagdelen, K. (1995). Optimal blending of mine production using goal programming and interactive graphics systems. International Journal of Surface Mining, Reclamation and Environment, 9(4), 203-208. https://doi.org/10.1080/09208119508964748

Creemers, S. (2018). Maximizing the expected net present value of a project with phase-type distributed activity durations: An efficient globally optimal solution procedure. European Journal of Operational Research, 267(1), 16-22. https://doi.org/10.1016/j.ejor.2017.11.027

Dagdelen, K., \& Kawahata, K. (2008). Value creation through strategic mine planning and cutoff-grade optimization. Mining Engineering, SME Publications, 39-45.

Dagdelen, K., \& Kawahata, K. (2007). Cut-off grade optimization for large scale multi-mine, multi-process mining operations. Proceedings of the International Symposium on Mine Planning and Equipment Selection, 226233.

Dehghani, H., \& Bogdanovic, D. (2018). Copper price estimation using bat algorithm. Resources Policy, 
55(March), 55-61. https://doi.org/10.1016/j.resourpol.2017.10.015

Dowd, P. A. (1976). Application of Dynamic and Stochastic Programming to Optimize Cutoff Grades and Production Rates. Transactions of the Institute of Mining and Metallurgy, Section A, 85, 22-31. https://doi.org/10.1590/S1516-18462008000300012

Dunna, J. A. (1942). Bulletin GSI. 23.

Fathollahzadeh, K., Mardaneh, E., Cigla, M., Waqar, M., \& Asad, A. (2021). International Journal of Mining Science and Technology A mathematical model for open pit mine production scheduling with Grade Engineering Ò and stockpiling. International Journal of Mining Science and Technology, xxxx, 1-12. https://doi.org/10.1016/j.ijmst.2021.03.011

Franco-sepulveda, G., Jaramillo, G. P., \& Rio, J. C. Del. (2019). Use of Genetic Algorithms for Optimization of Open-Pit Mining Operations with Geological and Market Uncertainty. In Proceedings of the 27th International Symposium on Mine Planning and Equipment Selection - MPES 2018. Springer International Publishing. https://doi.org/10.1007/978-3-319-99220-4

Ganguli, R., Dagdelen, K., \& Grygiel, E. (2011). Mine scheduling and cut-off grade optimization using mixed integer linear programming (3rd Edn). Chapter 9:10: Systems Engineering. SME Mining Engineering Handbook/.

Haonan, Z., Samavati, M., \& Hill, A. (2021). Heuristics for integrated blending optimisation in a mining supply chain. Omega, 102, 102373. https://doi.org/10.1016/j.omega.2020.102373

Henckens, M. L. C. M., \& Worrell, E. (2020). Reviewing the availability of copper and nickel for future generations. The balance between production growth, sustainability and recycling rates. Journal of Cleaner Production, 264. https://doi.org/10.1016/j.jclepro.2020.121460

Henning, U. (1963). Calculation of cut-off grade. Canadian Mining Journal, 84, 54-57.

Hustrulid, W., Kutcha, M., \& Martin, R. (2013). Open Pit Mine Planning \& Design. CRC Press, Taylor and Francis group.

Jamshidi, M., \& Osanloo, M. (2018). Optimizing mine production scheduling for multiple destinations of ore blocks. Bangladesh Journal of Scientific and Industrial Research, 53(2), 99-110. http://dx.doi.org/10.3329/bjsir.v53i2.36670

Jélvez, E., Morales, N., Nancel-Penard, P., \& Cornillier, F. (2020). A new hybrid heuristic algorithm for the Precedence Constrained Production Scheduling Problem: A mining application. Omega, 94. https://doi.org/10.1016/j.omega.2019.03.004

Jevons, W. S. (1866). The coal question (pp. xxvi, 383 p.). Macmillan and co. file://catalog.hathitrust.org/Record/000958706

Jowitt, S. M., Mudd, G. M., \& Thompson, J. F. H. (2020). Future availability of non-renewable metal resources and the influence of environmental, social, and governance conflicts on metal production. Communications Earth \& Environment, 1(1), 1-8. https://doi.org/10.1038/s43247-020-0011-0

King, B. (2000). Optimal Mine Scheduling Policies (PhD thesis). Imperial College of Science. Technology and Medicine Royal School of Mines.

King, W. (1886). Rec. GSI, 19(pt-3), 16-166.

Krausmann, F., Lauk, C., Haas, W., \& Wiedenhofer, D. (2018). From resource extraction to outflows of wastes and emissions: The socioeconomic metabolism of the global economy, 1900-2015. Global Environmental Change, 52(July), 131-140. https://doi.org/10.1016/j.gloenvcha.2018.07.003

Lane, K. F. (1964). Choosing the optimum cut-off grade. Colorado School of Mines Quarterly, 811-819.

Lane, K. F. (1988). The Economic Definition of Ore: Cutoff Grade in Theory and Practice. Mining Journal Books, London.

Li, S., \& Yang, C. (2012). An optimum algorithm for cut-off grade calculation using multistage stochastic programming. Journal of Theoretical and Applied Information Technology, 45(1), 117-122.

Long, K. R. (2009). A test and re-estimation of Taylor's empirical capacity-reserve relationship. Natural Resources Research, 18(1), 57-63. https://doi.org/10.1007/s11053-009-9088-y

Mudd, G. M. (2012). Key trends in the resource sustainability of platinum group elements. Ore Geology Reviews, 46, 106-117. https://doi.org/https://doi.org/10.1016/j.oregeorev.2012.02.005

Oraee, K., Sayadi, A. R., \& Tavassoli, S. M. M. (2011). Economic evaluation and sensitivity-risk analysis of Zarshuran gold mine project. SME Annual Meeting and Exhibit and CMA 113th National Western Mining Conference 2011, January, 126-131.

Peymankar, M., Davari, M., \& Ranjbar, M. (2021). Maximizing the expected net present value in a project with 
uncertain cash flows. European Journal of Operational Research, 294(2), 442-452. https://doi.org/10.1016/j.ejor.2021.01.039

Rezakhah, M., \& Newman, A. (2020). Computers and Operations Research Open pit mine planning with degradation due to stockpiling. Computers and Operations Research, 115, 1-8. https://doi.org/10.1016/j.cor.2018.11.009

Ricardo, D. (1821). On the Principles of Political Economy and Taxation. In Batoche Books, Kitchener. Batoche Books, Kitchener. http://socserv2.socsci.mcmaster.ca/ econ/ugcm/3113/michels/polipart.pdf

Russell, A. H. (1970). Cash Flows in Networks. Management Science, 16(5), 357-373. https://doi.org/10.1287/mnsc.16.5.357

Saleh, J. H., \& Marais, K. (2006). Reliability: How much is it worth? Beyond its estimation or prediction, the (net) present value of reliability. Reliability Engineering and System Safety, 91(6), 665-673. https://doi.org/10.1016/j.ress.2005.05.007

Samavati, M., Essam, D., Nehring, M., \& Sarker, R. (2018). A new methodology for the open-pit mine production scheduling problem. Omega, 81, 169-182. https://doi.org/10.1016/j.omega.2017.10.008

Sikka, D., \& Nehru, C. E. (1997). Review of Precambrian porphyry Cu \pm Mo \pm Au deposits with special reference to Malanjkhand porphyry copper deposit, Madhya Pradesh, India. Journal of the Geological Society of India, 49(3), 239-288.

Smith, A. (1776). The wealth of nations. Methuen \& Co.

Su, C. W., Wang, X. Q., Zhu, H., Tao, R., Moldovan, N. C., \& Lobonț, O. R. (2020). Testing for multiple bubbles in the copper price: Periodically collapsing behavior. Resources Policy, 65, 1-9. https://doi.org/10.1016/j.resourpol.2020.101587

Tahar, M. Ben, Slimane, S. Ben, \& Ali Houfi, M. (2021). Commodity prices and economic growth in commoditydependent countries: New evidence from nonlinear and asymmetric analysis. Resources Policy, 72(February), 1-8. https://doi.org/10.1016/j.resourpol.2021.102043

Taylor, H. K. (1972). General background theory of cut-off grades. Transactions of the Institution of Mining and Metallurgy:Section A, 160-179.

Taylor, H. K. (1986). Rates of working mines - a simple rule of thumb. Transactions of the Institution of Mining and Metallurgy:Section A, 95, A203-A204.

Teseletso, L. S., \& Adachi, T. (2021). Future availability of mineral resources: ultimate reserves and total material requirement. Mineral Economics, 0123456789. https://doi.org/10.1007/s13563-021-00283-2

Tolwinski. (1998). Scheduling production for open pit mines. APCOM '98 27th International Symposium on Computer Applications in the Minerals Industries (Fhe Institution of Mining and Metallurgy).

Van Vuuren, D. P., Strengers, B. J., \& De Vries, H. J. M. (1999). Long-term perspectives on world metal use-a system-dynamics model. Resources Policy, 25(4), 239-255. https://doi.org/https://doi.org/10.1016/S03014207(99)00031-8

Wang, Q. (1995). Long-term open-pit production scheduling through dynamic phase-bench sequencing. Transactions of the Institution of Mining and Metallurgy. Section A. Mining Industry, 105, A99-A104.

Wang, Qingfei, Deng, J., Zhao, J., Liu, H., Wan, L., \& Yang, L. (2010). Tonnage-cutoff model and average gradecutoff model for a single ore deposit. Ore Geology Reviews, 38(1-2), 113-120. https://doi.org/10.1016/j.oregeorev.2010.07.003

Wiesemann, W., Kuhn, D., \& Rustem, B. (2010). Maximizing the net present value of a project under uncertainty. European Journal of Operational Research, 202(2), 356-367. https://doi.org/10.1016/j.ejor.2009.05.045

Yasrebi, A. B., Wetherelt, A., Foster, P., Kennedy, G., Ahangaran, D. K., Afzal, P., \& Asadi, A. (2015). Determination of optimised cut-off grade utilising non-linear programming. Arabian Journal of Geosciences, 8, 8963-8967. https://doi.org/10.1007/s12517-014-1756-5 